\title{
Polymerisation, basicity, oxidation state and their role in ionic modelling of silicate melts
}

\author{
Roberto Moretti \\ Istituto Nazionale di Geofisica e Vulcanologia, Osservatorio Vesuviano, Napoli, Italy
}

\begin{abstract}
In order to describe and quantify the reactivity of silicate melts, the ionic notation provided by the Temkin formalism has been historically accepted, giving rise to the study of melt chemical equilibria in terms of completely dissociated ionic species. Indeed, ionic modelling of melts works properly as long as the true extension of the anionic matrix is known. This information may be attained in the framework of the Toop-Samis (1962a,b) model, through a parameterisation of the acid-base properties of the dissolved oxides. Moreover, by combining the polymeric model of Toop and Samis with the «group basicity» concept of Duffy and Ingram (1973, 1974a,b, 1976) the bulk optical basicity (Duffy and Ingram, 1971; Duffy, 1992) of molten silicates and glasses can be split into two distinct contributions, i.e. the basicity of the dissolved basic oxides and the basicity of the polymeric units. Application to practical cases, such as the assessment of the oxidation state of iron, require bridging of the energetic gap between the standard state of completely dissociated component (Temkin standard state) and the standard state of pure melt component at $P$ and $T$ of interest. On this basis it is possible to set up a preliminary model for iron speciation in both anhydrous and hydrous aluminosilicate melts. In the case of hydrous melts, I introduce both acidic and basic dissociation of the water component, requiring the combined occurrence of $\mathrm{H}^{+}$ cations, $\mathrm{OH}^{-}$free anions and, to a very minor extent, of $T$-OH groups. The amphoteric behaviour of water revealed by this study is therefore in line with the earlier prediction of Fraser (1975).
\end{abstract}

Key words polymerisation - basicity - oxidation state - water speciation - Temkin model

\section{Introduction}

During the last century many models have been proposed dealing with the thermodynamic properties of silicate melts (or slags), especially with the goal of understanding slag-melt partitioning of elements for industrial reasons relevant to steelmaking. The heuristic capability of a model assessing silicate melts energetics be-

Mailing address: Dr. Roberto Moretti, Istituto Nazionale di Geofisica e Vulcanologia, Osservatorio Vesuviano, Via Diocleziano 328, 80124 Napoli, Italy; e-mail: moretti@ov.ingv.it comes particularly important when dealing with the generalised problem of multicomponent, mutliphase equilibria, as shown by the thermochemical treatments presented in Ghiorso et al. (1983), Ghiorso and Sack (1994), Pelton (1998), Papale (1999) and Moretti et al. (2003). To model element solubility and speciation it is necessary to account fully for the compositional variables of the system. Nevertheless, compositional variables cannot be understood without a comprehensive model able to rescale measured concentrations in terms of component activities, which represent the obvious control parameters of chemical reactions taking place in the system. Therefore, the choice of the model for component activities represents a crucial step in silicate melt thermodynamics. Here, I will show that ionic models accounting for the variable degree of polymeri- 
sation represent suitable tools to model silicate melt reactivity.

The earliest theories on the constitution of silicate slags were developed as a result of mineralogical examination of the constituents of solidified melts and may be classified as molecular models. In 1923, Colclough (quoted in Gaskell, 2000), perhaps anticipating Bowen (1928), pointed out that, as the phases occurring in the solid state are formed by selective crystallisation from the melt, mineralogical examination cannot provide evidence that the compounds, observed in the solid state, had existed in the liquid. The concept of thermodynamic equilibrium was particularly stressed by Schenck (1945), who recognised that each reaction proceeds up to the achievement of equilibrium, independently of the extension of the system. In molecular models it is assumed that molecular complexes are formed in the melt in proportions dictated by the overall melt stoichiometry. Gaskell (2000) states that a common feature of molecular models is that «rather than the constitution of the slag being deduced from the observed behaviour, a set of arbitrary assumptions was manipulated to reproduce the observed behaviour. Comparison among the approaches shows that the degree of success of any model in giving the required reproduction is not sensitive to the finer details of the assumed constitution or to the internal thermodynamic consistency of the model». This recalls somehow the normative deconvolution adopted by Ghiorso et al. (1983) in their multicomponent free energy minimization procedure conducted in a regular solution approximation of the zeroth order. In fact this model does not account for the true nature of silicate melts and the choice of components reflects the topology of the compositional space investigated by the authors.

Most melts or slags are however «ionic» rather than «molecular» liquids. The existence of ions in the liquid state was already demonstrated in 1923 by Sauerwald and Neuendorff (quoted in Gaskell, 2000) who successfully electrolysed iron silicate melts, and in 1924 by Farup et al. (quoted in Gaskell, 2000) who measured the conductivity of melts in the systems $\mathrm{CaO}-\mathrm{SiO}_{2}$ and $\mathrm{CaO}-\mathrm{Al}_{2} \mathrm{O}_{3}-\mathrm{SiO}_{2}$.
Tamman (1931, quoted in Gaskell, 2000) already assumed electrolytic dissociation of metallurgical slags. A first application of an ionic theory of slags to the treatment of slag-metal equilibria was made by Herasymenko (1938) who assumed that slags were mixtures of $\mathrm{Fe}^{2+}$, $\mathrm{Mn}^{2+}, \mathrm{Ca}^{2+}, \mathrm{Al}^{3+}$ and $\mathrm{SiO}_{4}^{4-}$.

The need for an ionic model of silicate melts emerged clearly from the experimental determinations on viscosity and electrical conductivity. Further electrical conductivity measurements carried out by various authors indicate an essentially ionic unipolar conductivity (Bockris et al., 1952a,b; Bockris and Mellors, 1956; Waffe and Weill, 1975), where charge transfer evidently operates by cations, with anions being essentially stationary. Transference of electronic charges ( $h$ - and $n$-type conductivity) is observed only in melts enriched in transition elements, where band conduction and electron hopping phenomena are favoured. I will hereon dismiss the neutral molecular approach and accept that silicate melts, like other fused salts, are ionic liquids. In an ionic melt, coulombic forces acting between charges of opposite sign lead to a relative short-distance ordering of ions, with anions surrounded by cations and vice versa. The probability of finding a cation replacing an anion in such ordering is effectively zero and, from a statistical point of view, the melt can be considered a quasi-lattice, with two distinct sites, usually defined as «anion matrix» and «cation matrix».

The distinction between these two matrices was made by Temkin (1945), who considered that the electrostatic forces characterising ionic interactions are sufficiently strong to make the arrangements of ions in the pure fused salts and in mixture of salts similar to those in the crystalline state, implying co-ordination of cations by anions.

In the Temkin approach to fused salts, the activity of component $A Z$ in the ideal mixture of the two fused salts $A Z$ and $B Y$ is expressed by the Temkin equation

$$
a_{A Z, \text { melt }}=X_{A} X_{Z}=\frac{n_{A}}{n_{A}+n_{B}} \cdot \frac{n_{Z}}{n_{Z}+n_{Y}} .
$$

A straight application of the Temkin model to silicate melts is inadequate because the exten- 
sion of the anion matrix varies in a complicated fashion with composition. This complexity is reflected by activity-composition relationships deviating from the ideal Temkin model behaviour and may be fully accounted for by polymer chemistry.

\section{The Toop-Samis model}

In polymeric models of silicate melts, it is postulated that, at each composition, for given $P$ $T$ values, the melt is characterized by an equilibrium distribution of several ionic species of oxygen, metal cations and ionic silicate polymers.

The charge balance of a polymerization reaction involving $\mathrm{SiO}_{4}^{4-}$ monomers may be formally described by a homogenous reaction involving three forms of oxygen: singly bonded $\mathrm{O}$-, doubly bonded $\mathrm{O}^{0}$ (or «bridging oxygen»), and free oxygen $\mathrm{O}^{2-}$ (Fincham and Richardson, 1954)

$$
2 \mathrm{O}_{m}^{-} \Longleftrightarrow 2 \mathrm{O}_{m}^{0}+2 \mathrm{O}_{m}^{2-}
$$

Polymer chemistry shows that the larger the various polymers are, the more their reactivity is independent of the length of polymer chains. This fact, known as the "principle of equal reactivity of co-condensing functional groups», has been verified in fused polyphosphate systems, which are analogous, in several respects, to silicate melts ( $c f$. Fraser, 1977; Ottonello, 1997).

Assuming this principle to be valid, the equilibrium constant of reaction (2.1) becomes

$$
K_{2.1}=\frac{\left(\mathrm{O}^{0}\right)\left(\mathrm{O}^{2-}\right)}{\left(\mathrm{O}^{-}\right)^{2}} \text {. }
$$

Terms in parentheses represent the number of moles in the melt, which can be used in place of activities since all three species of oxygen speciate over the same matrix (anion matrix: the three oxygen types either mix ideally or their activity coefficients cancel out ).

Toop and Samis (1962 a,b) showed that in a binary melt $\mathrm{MO}-\mathrm{SiO}_{2}$ the total number of bonds per mole of melt is given by

$$
2\left(\mathrm{O}^{0}\right)+\left(\mathrm{O}^{-}\right)=4 N_{\mathrm{SiO}_{2}}
$$

where $N_{\mathrm{SiO}_{2}}$ are the moles of $\mathrm{SiO}_{2}$ in the MO$\mathrm{SiO}_{2}$ melt. The Toop and Samis model assumes the basic oxide MO to be completely dissociated. The number of bridging oxygens in the melt is thus

$$
\left(\mathrm{O}^{0}\right)=\frac{4 N_{\mathrm{SiO}_{2}}-\left(\mathrm{O}^{-}\right)}{2} .
$$

Mass balance gives the number of moles of free oxygen per unit mole of melt

$$
\left(\mathrm{O}^{2-}\right)=\left(1-N_{\mathrm{Si}_{2}}\right)-\frac{\left(\mathrm{O}^{-}\right)}{2}
$$

where obviously $1-N_{\mathrm{SiO}_{2}}$ represents the number of moles of basic oxide in the melt.

Combining the various equations one gets

$$
K_{2.1}=\frac{\left[4 N_{\mathrm{SiO}_{2}}-\left(\mathrm{O}^{-}\right)\right]\left[2-2 N_{\mathrm{SiO}_{2}}-\left(\mathrm{O}^{-}\right)\right]}{4\left(\mathrm{O}^{-}\right)^{2}}
$$

which reduces to a quadratic equation in $\left(\mathrm{O}^{-}\right)$

$$
\begin{aligned}
& \left(\mathrm{O}^{-}\right)^{2}\left(4 K_{2.1}-1\right)+\left(\mathrm{O}^{-}\right)\left(2+2 N_{\mathrm{SiO}_{2}}\right)+ \\
& +8 N_{\mathrm{SiO}_{2}}\left(N_{\mathrm{SiO}_{2}}-1\right)=0 .
\end{aligned}
$$

Given $N_{\mathrm{SiO}_{2}}$, eq. (2.7) may be solved.

Since the number of oxygens which react according to eq. (2.2) is $\left(\mathrm{O}^{-}\right) / 2$ per mole of melt, the free energy of mixing per mole of melt is

$$
\Delta G_{\text {mixing }}=\left[\left(\mathrm{O}^{-}\right) / 2\right] R T \ln K_{2.1} .
$$

The validity of this equation has been proved many times (see for example Fraser, 1975; Ottonello, 1997; Ottonello et al., 2001).

\section{Polymerisation and acid-base properties}

It is evident that the reaction (2.1) between the three oxygen species represents the characteristic process of an acid-base reaction in oxide systems, which was defined by Flood and Förland (1947) as «the transfer of an oxygen ion from a state of polarisation to another». This acceptance is particularly important in silicate melts and glasses where polymerisation reactions governing extension and distribution of polymeric units may be restated as (as already shown) simple 
acid-base reactions involving three distinct polarisation states of oxygen (see eq. (2.2)).

Although the Lux-Flood formulation formally differs from a Brönsted-Lowry (protonbased) exchange, the two formulations are mutually consistent (Flood and Förland, 1947) and, with this proviso, the link between redox and acid-base exchanges in the Lux-Flood acceptation is represented by the «normal oxygen electrode» equilibrium

$$
\frac{1}{2} \mathrm{O}_{2}+2 \mathrm{e}^{-} \Longleftrightarrow \mathrm{O}^{2-} .
$$

Thus in aprotic solvents $\mathrm{O}^{2-}$ replaces $\mathrm{H}^{+}$. A basic oxide is the one capable of furnishing oxygen ions and an acidic oxide is one that associates oxygen ions

$$
\text { Base } \Longleftrightarrow \text { Acid }+\mathrm{O}^{2-} \text {. }
$$

It is well established that the Lux-Flood acidbase property of dissolved oxides markedly affects the extent of polymerisation by producing or consuming free oxygen ions $\left(\mathrm{O}^{2-}\right)$. Thus, for a generic oxide MO (Fraser, 1975, 1977):

$$
\begin{aligned}
& \mathrm{MO}+\mathrm{O}^{2-} \Longleftrightarrow \mathrm{MO}_{2}^{2-} \\
& \mathrm{MO} \Longleftrightarrow \mathrm{MO}^{2+}+\mathrm{O}^{2-}
\end{aligned}
$$

with (3.3) and (3.4) showing acidic and basic behaviours, respectively. Although it is conceptually immediate to envisage directly a direct relationship between polymerisation constant $\left(K_{2}\right)$ and basicity of dissolved oxides in binary systems (Toop and Samis, 1962,a,b), the extension to multicomponent melts and glasses is not immediate. Moreover, in the presence of altervalent elements such as Fe, mutual interactions are established between the normal oxygen electrode reaction (3.1) and the dissociation equilibria ((3.3)-(3.4)). These may be addressed by taking into account both the polymeric nature of the anion matrix, along the guidelines of the Toop-Samis model, and Fraser's amphotheric treatment of dissolved oxides.

In a chemically complex melt or glass, the capability of transferring fractional electronic charges from the ligands to the central cation depends in a complex fashion on the melt or glass structure, which affects the polarisation state of the ligand itself. The mean polarisation state of the various ligands (mainly oxide ions in natural silicate melts) and their ability to transfer fractional electronic charges to the central cation are nevertheless conveniently represented by an experimentally observable parameter which is an index of the basicity of the medium: the optical basicity (see Duffy, 1992 for an exhaustive review of the subject). A formal link is thus needed between polymerisation constant and optical basicity.

\section{The «optical basicity» concept}

As we have already seen there are strict mutual interconnections between the concepts of «oxidation state» and «basicity», whenever this last term is referred to non-protonated systems. Following Jørgensen (1969) we may define oxidation by means of four distinct formalisms:

- Formal oxidation number denoted by Roman numeral superscripts (including the non-Roman notations $0,-\mathrm{I}, \ldots$ ) whenever this does not imply an accurate description of the true nature of the complex (i.e. $\mathrm{Ni}^{\mathrm{II}}$ for nickel in the aqueous complex $\mathrm{Ni}\left(\mathrm{H}_{2} \mathrm{O}\right)_{6}^{2+}$ or $\mathrm{S}^{\mathrm{VI}}$ in the sulphate complex $\mathrm{SO}_{4}^{2-}$ ).

- Spectroscopic oxidation states derived by experimentally observed excited levels, denoted by on-line Roman numerals in parentheses; i.e. $\mathrm{Cr}(\mathrm{III}) \mathrm{O}_{6}, \mathrm{Ni}(\mathrm{II}) \mathrm{C}_{16}$, etc.

- Conditional oxidation states derived from electronic configuration; i.e. $[\mathrm{Ar}] 3 d^{5}$ for $\mathrm{Mn}^{2+}, \mathrm{Fe}^{2+}$, etc.

- Distributed oxidation states adjacent atoms bonded in the complex share the electrons equally; i.e. $\mathrm{C}\langle 0\rangle$ and $\mathrm{H}\langle 0\rangle$ in $\mathrm{CH}_{4} ; \mathrm{S}\langle 0\rangle$ and $\mathrm{O}\langle-\mathrm{I}\rangle$ in $\mathrm{SiO}_{4}{ }^{4-}$ etc.

The usual notation with arabic numeral superscripts (i.e. $\mathrm{Li}^{+}, \mathrm{Mg}^{2+}, \mathrm{Cr}^{3+}, \mathrm{F}^{-}$) which we will hereafter refer to «formal ionic charges» should be reserved for cases in which «entities and molecules are sufficiently separated and are either neutral or carry charges which are a positive or negative integer multiplied by the protonic charge» (Jørgensen, 1969).

In Brönsted's formalism, redox reactions are those involving exchange of electrons be- 
tween the reactants and acid-base reactions are those involving protons. The Brönsted acidbase function for protonated systems is usually represented as

$$
\text { Acid } \Longleftrightarrow \text { Base }+\mathrm{H}^{+} \text {. }
$$

The link joining redox and acid-base reactions is the normal hydrogen electrode reaction

$$
2 \mathrm{e}^{-}+2 \mathrm{H}^{+} \Longleftrightarrow \mathrm{H}_{2}
$$

As in non-protonated systems the BrönstedLowry formalism is better replaced by the LuxFlood acid-base definition (Flood and Förland, 1947), three sorts of transitions are involved in acid-base equilibria:

i) Transitions accompanied by an alteration of the co-ordination number of oxygen, but no change of distributed oxidation state, for atoms with a high ionisation energy, such as for example in

$$
\mathrm{CO}\langle 0\rangle_{3}^{2-} \Longleftrightarrow \mathrm{CO}\langle 0\rangle_{2}+\mathrm{O}^{2-} .
$$

ii) Transitions which do not involve any change in co-ordination number, but a change in distributed oxidation state, for medium ionisation energy atoms, such as in

$$
\mathrm{SiO}\langle-\mathrm{I}\rangle_{4}^{4-} \Longleftrightarrow \mathrm{SiO}\langle 0\rangle_{2}+2 \mathrm{O}^{2-}
$$

iii) Transitions which involve both change in co-ordination number and in distributed oxidation state, leading to the formation of isolated cations, such as occurring for low ionisation energy atoms

$$
\mathrm{CaO}\langle 0\rangle \Longleftrightarrow \mathrm{Ca}^{2+}+\mathrm{O}^{2-} .
$$

In silicate melts we envisage simple acid-base reactions involving three distinct polarisation states of oxygen, eq. (2.1), which in a distributed oxidation state notation may be expressed as follows:

$$
2 \mathrm{O}\langle-\mathrm{I}\rangle^{-} \Longleftrightarrow \mathrm{O}\langle 0\rangle+\mathrm{O}^{2-} .
$$

Although formally different, the BrönstedLowry and the Lux-Flood formulations are mu- tually consistent and, if we still accept the Brönsted definition of redox reactions, then it may be readily seen that the link joining redox and acid-base exchanges in the Lux-Flood acceptation is now represented by the oxygen electrode equilibrium.

The fact that reaction (3.1) could also resemble an equilibrium between a Lewis acid (i.e. a substance acting as acceptor of a pair of electrons; $\mathrm{O}_{2}$ in our case) and a Lewis base (i.e. a substance acting as donor of a pair of electrons; $\mathrm{O}^{2-}$ in our case), leading to a stable octet configuration, further emphasises the necessity of distinguishing a redox equilibrium, i.e. «a reaction involving free electrons (in the broad sense of the term) and resulting in a change of formal oxidation number» from an acid-base equilibrium which, in the Brönsted-Lowry formalism is basically «the transfer of an oxygen ion from a state of polarisation to another», as already noted.

Although we may conceive formal integer charges for isolated non-interacting (gaseous) ions (i.e. $\mathrm{Li}^{+}, \mathrm{Mg}^{2+}, \mathrm{Fe}^{3+}$, etc.) and (although much less evidently) for isolated complexes, this formalism cannot be readily transferred to the formal oxidation state within a complex since, in most cases, it is in contrast with both the quantum-mechanical concept of «electron density» and with the notion of «fractional ionic character of a bond» (Pauling, 1932, 1960; Gordy, 1950; Hinze et al., 1963; Phillips, 1970, see below). Moreover, in a chemically complex melt or glass the capability of transferring fractional electronic charges from the ligands to the central cation depends in a complex fashion on the melt structure, which affects the polarisation state of the ligand itself. The mean polarisation state of the various ligands (mainly oxide ions in natural silicate melts) and their ability to transfer fractional electronic charges to the central cation are nevertheless conveniently represented by the «optical basicity» of the medium (Duffy and Ingram, 1971). The concept of optical basicity arises primarily from the systematic study of the orbital expansion (or «nephe-lauxetic effect») induced by an increased localised donor pressure on $p$-block metals. Metal ions such as $\mathrm{Tl}^{\mathrm{I}}$ (group III), $\mathrm{Pb}^{\mathrm{II}}$ (group IV), $\mathrm{Bi}^{\mathrm{III}}$ (group V) (i.e. oxidation number = group number -2 ) have an electron pair in the outermost 
$(6 s)$ orbital. When trace concentrations of the metal are dissolved in melts and glasses, coordination with the ligand field anions results in formation of Molecular Orbitals (MOs) which increase the electron density of the inner shells. The consequent shielding of nuclear charges affects the energy involved in the outermost $6 s \rightarrow 6 p$ transitions which become lower the more the inner shell electron density is increased. Lowering of the $6 s \rightarrow 6 p$ transition energy is experimentally observed as a dramatic red-ward shift of the $6 s \rightarrow 6 p$ UV absorption band when the $p$-block free ion is immersed in a ligand field. The spectroscopic shift of the ${ }^{1} \mathrm{~S}_{0} \rightarrow{ }^{3} \mathrm{P}_{1}$ absorption band experienced by $\mathrm{Pb}$ when passing from a free ion $\left(\mathrm{Pb}^{2+}\right)$ condition to $\mathrm{Pb}^{\mathrm{II}}$ in an $\mathrm{O}^{2-}$ ligand field is for instance $60700-29700=31000 \mathrm{~cm}^{-1}$ (Duffy and Ingram, 1971, 1974b, 1976). For Bi ${ }^{\mathrm{III}}$ the analogous redward shift is $28.8 \mathrm{kK}(1 \mathrm{kK}=$ $1000 \mathrm{~cm}^{-1}$ ) and is $18.3 \mathrm{kK}$ for $\mathrm{Tl}^{\mathrm{I}}$.

This phenomenon is quantitatively understood in terms of ligand field theory by analogy with the behavior of $3 d, 4 d$ and $5 f$ transition ions (Jørgensen, 1962, 1969; and references therein). In octahedral $3 d$ chromophores for example, the energy splitting between anti bonding $\Psi_{z^{2}}^{*}, \Psi_{x^{2}-y^{2}}^{*}$ MOs and the $d_{x y}, d_{x z}, d_{y z}$ AOs of the central atom $\left(\Delta_{\text {cov- } \sigma}\right)$ is linearly affected by the position of the ligand in the spectrochemical series (represented by parameter $f$ ) and by a representative parameter of the central cation $(g)$, according to the simple relationship (Jørgensen, 1969)

$$
\Delta_{\text {cov- } \sigma}=f_{\text {(ligand) }} \cdot g_{\text {(cation) }} .
$$

The precision achieved by this simple equation in describing $\Delta_{\text {cov- } \sigma}$ in $3 d^{3}, 3 d^{6}$ and $3 d^{8}$ chromophores is remarkable ( $c f$. table 5.8 in Jørgensen, 1969). However, the energy shift induced by changes in $\mathrm{f}$ is not so marked as to allow a basicity scale to be proposed on the basis of eq. (4.7) ( $c f$. table 5.5. in Jørgensen, 1969).

Jørgensen (1962) pointed out that the expansion of the radial function consequent on lowering of the effective nuclear charge $\left(Z_{\text {eff }}\right)$ results in three distinct nephelauxetic parameters $(\beta)$. These are $\beta_{l l}$ for the interaction between two electrons in the lower sub-shell, $\beta_{l u}$. for the interaction between an electron in the lower and an electron in the upper sub-shell and $\beta_{u и}$ for the interaction between two electrons in the upper sub-shell

$$
\begin{gathered}
\beta_{l l}=a_{l}^{4} \frac{Z_{\mathrm{eff}}}{Z_{\mathrm{eff}}^{*}} \\
\beta_{l u}=a_{l}^{2} a_{u}^{2} \frac{Z_{\mathrm{eff}}}{Z_{\mathrm{eff}}^{*}} \\
\beta_{u u}=a_{u}^{4} \frac{Z_{\mathrm{eff}}}{Z_{\mathrm{eff}}^{*}}
\end{gathered}
$$

$Z_{\mathrm{eff}}^{*}$ in the above equations is the effective nuclear charge of the free cation; $a$ is related to the mean radial distance of the orbital from the centre of nuclear charges and $\beta_{l l}>\beta_{l u}>\beta_{u u}$. According to Duffy and Ingram (1971) the optical basicity, $\Lambda$, is represented by the ratio $h / h^{*}$ where $h$ is the Jørgensen's (1962) function of the ligand in the polarisation state of interest and $h^{*}$ is the same function relative to the ligand in an unpolarised state (i.e. free $\mathrm{O}^{2-}$ ions in an oxide medium)

$$
\Lambda=\frac{h}{h^{*}}=\frac{1-\beta}{1-\beta^{*}}=\frac{\nu_{\text {free }}-\nu_{\text {glass }}}{\nu_{\text {free }}-\nu^{*}}
$$

with $v_{\text {free }}={ }^{1} \mathrm{~S}_{0} \rightarrow{ }^{3} \mathrm{P}_{1}$ absorption band of the free $p$-block cation; $v_{\text {glass }}={ }^{1} \mathrm{~S}_{0} \rightarrow{ }^{3} \mathrm{P}_{1}$ absorption band measured in the glass; $v^{*}={ }^{1} \mathrm{~S}_{0} \rightarrow{ }^{3} \mathrm{P}_{1}$ absorption band in a free $\mathrm{O}^{2-}$ medium.

As we see in fig. 1, the optical basicity of simple oxides appears related to the atomistic properties of the intervening cations, such as the Pauling and Sanderson's electronegativities $\left(\chi_{P}\right.$ and $\chi_{S}$ respectively) or the free ion polarizability (Young et al., 1992).

Although Duffy and Ingram (1974a) suggest a simple linear dependency between the reciprocal of optical basicity $\Lambda$ (or «basicity moderating parameter» $\gamma$; see later) and Pauling electronegativity $\chi_{P}$ (straight line in fig. 1), here I focus attention on the fact that a strict connection between optical basicity and bond ionicity should exist. The true nature of this relationship (which we depict as a second order polynomial dependency in the same figure) can be envisaged by equating the spectroscopic definition of fractional ionic character of a bond (Phillips, 


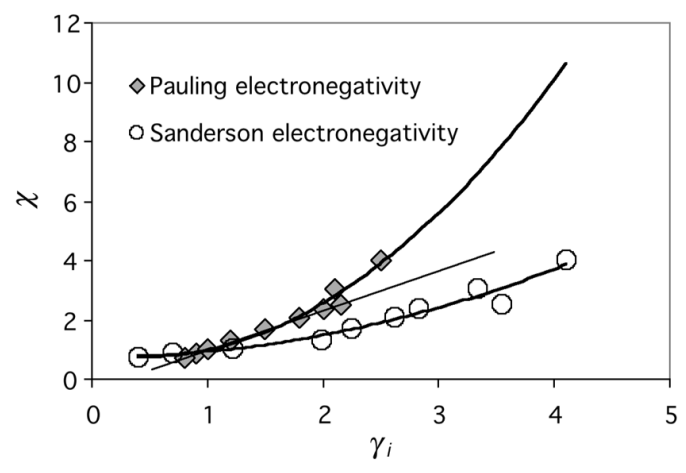

Fig. 1. Pauling and Sanderson electronegativities and basicity moderating parameter. The straight line is the intepolation of Duffy and Ingram (1974), $\gamma=1.36 \times\left(\chi_{P}-0.26\right)$.

1970) with Pauling notation

$$
f_{i}=\frac{E_{i}^{2}}{\left(E_{i}^{2}+E_{c}^{2}\right)}=1-\exp \left[-\frac{1}{4}\left(\chi_{\circ}-\chi_{\mathrm{M}}\right)\right]
$$

where $\chi_{\mathrm{O}}$ and $\chi_{\mathrm{M}}$ are respectively the Pauling electronegativity of oxygen and metal and

$$
E_{i}=\left(E_{g}^{2}+E_{c}^{2}\right)^{\frac{1}{2}} .
$$

$E_{i}$ in eq. (4.13) is the «ionic energy gap» and $E_{g}$ is the total energy gap between bonding and anti bonding orbitals ( $E_{c}$ corresponds to $E_{g}$ for the non-polar covalent bond in the same row of the periodic table, with a correction for inter-atomic spacing)

$$
E_{g}=\frac{\hbar \omega_{P}}{\left(\varepsilon_{\infty}-1\right)^{\frac{1}{2}}}
$$

with $\hbar \omega_{P}=$ plasma frequency for valence electrons; and $\varepsilon_{\infty}=$ optical dielectric constant.

The operational relationship between fractional ionic character of the bond in the oxide and optical basicity is the following:

$$
\Lambda=\left(4.6242-4.6702 f_{i}\right)^{-1} \quad R^{2}=0.9517 .
$$

Based on eqs. (4.12) and (4.15) we get the following approximation:

$$
\Lambda \approx \frac{1}{4.6\left(1-\frac{E_{i}^{2}}{E_{i}^{2}+E_{c}^{2}}\right)}
$$

which suggests an optical basicity of 0.225 for a purely covalent non polar bond (see also eq. (4.13)). This value compares favourably with the value $0.46 \div 0.48$ indicated by Duffy and Ingram (1974a) for $\mathrm{SiO}_{2}$ which has a fractional ionic character around 0.5 (0.516 according to Pauling, 1960).

The reciprocal of optical basicity («basicity moderating parameter» $\gamma_{\mathrm{M}}$, according to Duffy and Ingram, 1973) represents the tendency of an oxide forming cation $\mathrm{M}$ to reduce the localised donor properties of oxide ions. It is related to the optical basicity of the medium by

$$
\gamma_{\mathrm{M}}=\frac{Z_{\mathrm{M}} \times r_{\mathrm{M}}}{\left|Z_{\mathrm{M}}\right| \times \Lambda_{\mathrm{MO}}}
$$

where $Z_{\mathrm{M}}$ = formal oxidation number of cation $\mathrm{M}$ in $\mathrm{MO} ; Z_{\mathrm{O}}=$ formal oxidation number of oxide ion in $\mathrm{MO} ; r_{\mathrm{M}}=$ stoichiometric ratio between number of cations $\mathrm{M}$ and number of total oxide ions in the medium.

Although $\gamma_{M}$ reduces to in a simple single oxide medium, it has the property to describe the additive Jorgensen's $h$ function in chemically complex media (with $A, B, \ldots$ oxide forming cations) according to (Duffy and Ingram, 1973):

$$
\begin{aligned}
& h=h^{*}\left[1-\frac{Z_{A} \times r_{A}}{\left|Z_{O}\right|}\left(1-\frac{1}{\gamma_{\mathrm{A}}}\right)-\frac{Z_{B} \times r_{B}}{\left|Z_{\mathrm{O}}\right|} .\right. \\
& \left.\left(1-\frac{1}{\gamma_{\mathrm{B}}}\right)-\ldots\right] .
\end{aligned}
$$

Moreover, based on eqs. (4.16) and (4.17) the optical basicity of the medium may be expressed as

$$
\Lambda=\frac{Z_{A} \times r_{A}}{2 \gamma_{A}}+\frac{Z_{B} \times r_{B}}{2 \gamma_{B}}+\ldots
$$

Direct estimates of the basicity moderating parameter of the central cation may then be obtained from electronegativies (fig. 1) by appli- 
cation of the second order polynomials

$$
\begin{array}{r}
\gamma=0.8969-0.6703 \chi_{P}+0.7404 \chi_{P}^{2}\left(R^{2}=0.97\right) \\
(4.20) \\
\gamma=0.7398-0.0193 \chi_{S}+0.1880 \chi_{S}^{2}\left(R^{2}=0.96\right) .
\end{array}
$$

Equation (4.20), although conceptually less obvious than (4.16), is operationally more accurate and has been adopted by Ottonello et al. (2001) to evaluate basicity parameters, whenever literature values were controversial or lacking.

Table I summarises the functional relationships among the previously discussed parameters.

Table I. Optical basicity $\Lambda$ and basicity moderating parameter of the central cation $\gamma$ according to various sources. Pauling's and Sanderson's electronegativities (Pauling, 1932, 1960; Sanderson, 1967) are also listed. $\Lambda$,

\begin{tabular}{|c|c|c|c|c|c|c|c|c|c|c|}
\hline \multirow[t]{2}{*}{ Oxide } & \multicolumn{6}{|c|}{$\Lambda$} & \multicolumn{2}{|c|}{$\gamma$} & \multirow[t]{2}{*}{$\chi_{P}$} & \multirow[t]{2}{*}{$\chi_{s}$} \\
\hline & (1) & (2) & (3) & (4) & (5) & (6) & (6) & (7) & & \\
\hline $\mathrm{H}_{2} \mathrm{O}$ & & & 0.40 & & & 0.39 & 2.56 & 2.50 & 2.15 & 3.55 \\
\hline $\mathrm{Li}_{2} \mathrm{O}$ & & & & & & 1.00 & 1.00 & & 1.0 & 0.74 \\
\hline $\mathrm{B}_{2} \mathrm{O}_{3}$ & & & 0.42 & & & 0.42 & 2.38 & & 2.0 & 2.84 \\
\hline $\mathrm{Na}_{2} \mathrm{O}$ & & 1.15 & 1.15 & 1.15 & 1.15 & 1.15 & 0.87 & 0.87 & 0.9 & 0.70 \\
\hline $\mathrm{MgO}$ & 0.78 & 0.78 & 0.78 & 0.78 & 0.78 & 0.78 & 1.28 & 1.28 & 1.2 & 1.99 \\
\hline $\mathrm{Al}_{2} \mathrm{O}_{3}$ & 0.60 & 0.60 & 0.60 & 0.61 & 0.59 & 0.59 & 1.69 & 1.67 & 1.5 & 2.25 \\
\hline $\mathrm{SiO}_{2}$ & 0.48 & 0.46 & 0.48 & 0.48 & 0.48 & 0.48 & 2.09 & 2.09 & 1.8 & 2.62 \\
\hline $\mathrm{P}_{2} \mathrm{O}_{5}$ & 0.40 & 0.40 & 0.33 & 0.8 & 0.40 & 0.40 & 2.50 & 2.50 & 2.1 & 3.34 \\
\hline $\mathrm{SO}_{3}$ & 0.33 & & 0.25 & & & 0.33 & 3.03 & 3.03 & 2.5 & 4.11 \\
\hline $\mathrm{K}_{2} \mathrm{O}$ & & 1.40 & 1.4 & 1.40 & 1.40 & 1.36 & 0.74 & 0.71 & 0.8 & 0.41 \\
\hline $\mathrm{CaO}$ & 1.00 & 1.00 & 1.00 & 1.00 & 1.00 & 0.99 & 1.00 & 1.00 & 1.0 & 1.22 \\
\hline $\mathrm{TiO}_{2}$ & & 0.65 & & 0.61 & 0.61 & 0.58 & 1.72 & 1.54 & 1.6 & 1.60 \\
\hline $\mathrm{Cr}_{2} \mathrm{O}_{3}$ & 0.70 & & & & & 0.58 & 1.72 & & 1.6 & 1.88 \\
\hline $\mathrm{MnO}$ & $0.94-1.03$ & 0.98 & & 0.90 & 0.59 & 0.59 & 1.69 & 1.69 & 1.5 & 2.07 \\
\hline $\mathrm{FeO}$ & 0.86-1.08 & 1.03 & 1.00 & 1.03 & 0.51 & 0.48 & 2.09 & 1.354 & 1.8 & 2.10 \\
\hline $\mathrm{Fe}_{2} \mathrm{O}_{3}$ & $0.73-0.81$ & 0.77 & & 1.21 & 0.48 & 0.48 & 2.09 & 2.09 & 1.8 & 2.10 \\
\hline $\mathrm{CoO}$ & & & & & & 0.51 & 1.96 & 1.96 & 1.7 & 2.10 \\
\hline $\mathrm{NiO}$ & & & & & & 0.48 & 2.09 & 2.09 & 1.8 & 2.10 \\
\hline $\mathrm{Cu}_{2} \mathrm{O}$ & & & & & & 0.43 & 2.30 & 2.30 & 1.9 & 2.60 \\
\hline $\mathrm{ZnO}$ & & $.82-0.98$ & & & & 0.58 & 1.72 & 1.72 & 1.6 & 2.84 \\
\hline $\mathrm{SrO}$ & 1.10 & & & & & 1.03 & 0.97 & & 1.0 & 1.00 \\
\hline $\mathrm{SnO}$ & & & & & & 0.48 & 2.09 & 2.09 & 1.8 & 3.10 \\
\hline $\mathrm{BaO}$ & 1.15 & 1.15 & & 1.15 & 1.15 & 1.12 & 0.89 & & 0.9 & 0.78 \\
\hline $\mathrm{PbO}$ & & & & & & 0.48 & 2.09 & 2.09 & 1.8 & 3.08 \\
\hline
\end{tabular}
$\gamma, \chi_{S}$ : adimensional; $\chi_{P}$ : eV (from Ottonello et al., 2001).

(1) Duffy (1992); (2) Young et al. (1992); (3) Duffy and Ingram (1974a,b); (4) Sosinsky and Sommerville (1986); (5) Gaskell (1982); (6) Ottonello et al. (2001); eq. (4.19) (note that $\Lambda=\gamma^{-1}$ ); (7) Ottonello et al. (2001); obtained by non linear minimization of $\mathrm{FeO}$ thermodynamic activity data in multicomponent melts. 


\subsection{Group basicity}

Since we have established that the experimentally derived concept of optical basicity is related to atomistic properties and first principles such as Pauling's electronegativity and fractional ionic character of a bond (or «bond order») (see eqs. (4.12), (4.15) and (4.16)) we may tentatively extend the concept to formal entities such as the silica polymers (or «structons» in the sense of Fraser, 1975, 1977) within binary joins and then to complex melts. To address the problem we may still use eq. (4.19) but now the cation to oxide ratio represents the local coordination present in the structon (Duffy and Ingram, 1976). For instance, for a monomer $\mathrm{SiO}_{4}^{4-} r_{A}=\mathrm{M} / \mathrm{O}\langle-\mathrm{I}\rangle=1 / 4$, for a dimer $\mathrm{Si}_{2} \mathrm{O}_{7}^{6-}$ (or $\mathrm{Si}\langle 0\rangle_{2} \mathrm{O}\langle 0\rangle \mathrm{O}\langle-\mathrm{I}\rangle_{6}^{6-}$ in distributed oxidation state notation) $r_{A}=1 / 3$, and so on. Group basicities of the most important polymer units present in silicate melts are listed in table II. We may note that, with the increase of

Table II. Basicities of «structons» along the polymerisation path.

\begin{tabular}{|c|c|c|}
\hline Group & $\frac{Z_{A} \times r_{A}}{2}$ & Group basicity \\
\hline $\mathrm{SiO}_{4}^{4-}$ & 0.50000 & 0.73923 \\
\hline $\mathrm{AlO}_{4}^{5-}$ & 0.37500 & 0.85227 \\
\hline $\mathrm{FeO}_{4}^{5-}$ & 0.37500 & 0.80443 \\
\hline $\mathrm{Si}_{2} \mathrm{O}_{7}^{6-}$ & 0.57143 & 0.70198 \\
\hline $\mathrm{Al}_{2} \mathrm{O}_{7}^{11-}$ & 0.42857 & 0.83117 \\
\hline $\mathrm{Fe}_{2} \mathrm{O}_{7}^{11-}$ & 0.42857 & 0.77649 \\
\hline $\mathrm{SiAlO}_{7}^{7-}$ & - & 0.76658 \\
\hline $\mathrm{SiFeO}_{7}^{7-}$ & - & 0.73924 \\
\hline $\mathrm{Si}_{3} \mathrm{O}_{10}^{8-}$ & 0.60000 & 0.68707 \\
\hline $\mathrm{Si}_{4} \mathrm{O}_{13}^{10-}$ & 0.61538 & 0.67906 \\
\hline $\begin{array}{l}\mathrm{SiO}_{3-}^{2-} ; \mathrm{Si}_{2} \mathrm{O}_{6}^{4-} ; \mathrm{Si}_{3} \mathrm{O}_{9}^{6-} ; \\
\mathrm{Si}_{4} \mathrm{O}_{12}^{8-} ; \mathrm{Si}_{5} \mathrm{O}_{15}{ }^{10-} ; 1-\text {-ring }\end{array}$ & 0.66667 & 0.65231 \\
\hline $\begin{array}{l}\mathrm{Si}_{2} \mathrm{O}_{5}^{2-} ; \mathrm{Si}_{4} \mathrm{O}_{10}{ }^{4-} ; \mathrm{Si}_{6} \mathrm{O}_{15}{ }^{6-} \\
\mathrm{Si}_{8} \mathrm{O}_{20} 0^{8-} ; \mathrm{Si}_{10} \mathrm{O}_{25}{ }^{10-} ; 2 \text {-rings }\end{array}$ & 0.80000 & 0.58278 \\
\hline $\begin{array}{l}\mathrm{Si}_{3} \mathrm{O}_{7}^{2-} ; \mathrm{Si}_{9} \mathrm{O}_{21}{ }^{6-} ; \mathrm{Si}_{12} \mathrm{O}_{28}{ }^{9-} \\
\text { 3-rings }\end{array}$ & 0.85714 & 0.55297 \\
\hline $\mathrm{SiO}_{2}$ & 1.00000 & 0.47847 \\
\hline $\mathrm{Al}_{2} \mathrm{O}_{3}$ & 1.00000 & 0.60606 \\
\hline $\mathrm{Fe}_{2} \mathrm{O}_{3}$ & 1.00000 & 0.47847 \\
\hline
\end{tabular}

polymerisation, the group basicity of polymer chains progressively decreases due to the decrease of the ratio $\mathrm{O}\langle-\mathrm{I}\rangle / \mathrm{O}\langle 0\rangle$. We may also note that the presence of foreign cations (i.e. $\mathrm{Al}^{\mathrm{III}}$, $\left.\mathrm{Fe}^{\mathrm{III}}\right)$ in the polymer units changes the group basicity in a linear fashion with respect to the group stoichiometry.

We may now inquire if, based on this new concept, the basicity of a complex medium such as a silicate melt or glass may be expected to vary linearly with composition along a binary join.

For this purpose the three forms of oxygen present in the melt (i.e. $\mathrm{O}^{2-}, \mathrm{O}\langle-\mathrm{I}\rangle$ and $\mathrm{O}\langle 0\rangle$ ) (Toop and Samis, 1962a,b) are related to melt stoichiometry and to the polymerisation reaction constant $K_{2}$ by mass balance (eqs. (2.4), (2.5), (2.7)).

Along the polymerisation path (from monomers $\mathrm{SiO}_{4}{ }^{4-}$ to silica), the group basicity of the polyanion (or structon) matrix, $\Lambda_{« \text { structons», }}$ may be expressed as a linear function of the ratio between singly bonded oxygen and total oxygen within the structons (see also table II)

$$
\Lambda_{\text {structons }}=\frac{(\mathrm{O}\langle-\mathrm{I}\rangle)}{(\mathrm{O}\langle-\mathrm{I}\rangle)+(\mathrm{O}\langle 0\rangle)}\left(1-\Lambda_{\mathrm{SiO}_{4}^{4-}}\right)+\Lambda_{\mathrm{SiO}^{2}}
$$

where $\Lambda_{\mathrm{SiO}_{4}^{4-}}, \Lambda_{\mathrm{SiO}_{2}}$ are respectively the group basicity of the $\mathrm{SiO}_{4}^{4-}$ monomer and of the $\mathrm{SiO}_{2}$ tectosilicate. The bulk basicity of the medium results expressed as

$$
\begin{aligned}
& \Lambda_{\text {medium }}=\frac{\left(\mathrm{O}^{2-}\right)}{\sum \mathrm{O}} \Lambda_{\mathrm{MO}}-\frac{0.5 \times(\mathrm{O}\langle-\mathrm{I}\rangle)}{\sum \mathrm{O}}\left(1-\Lambda_{\mathrm{MO}}\right)+ \\
& +\frac{(\mathrm{O}\langle-\mathrm{I}\rangle)}{\sum \mathrm{O}}\left(1-\Lambda_{\mathrm{SiO}_{4}^{4}}\right)+\frac{(\mathrm{O}\langle-\mathrm{I}\rangle)+(\mathrm{O}\langle 0\rangle)}{\sum \mathrm{O}} \Lambda_{\mathrm{SiO}_{2}}
\end{aligned}
$$

where

$$
\sum \mathrm{O}=(\mathrm{O}\langle-\mathrm{I}\rangle)+(\mathrm{O}\langle 0\rangle)+\left(\mathrm{O}^{2-}\right)
$$

and $\Lambda_{\mathrm{MO}}$ is the basicity of the oxide in the binary join $\mathrm{MO}-\mathrm{SiO}_{2}$.

By combining eq. (4.23) with the mass balances (2.4), (2.5) and (2.7) we may evaluate which part of the bulk basicity of the medium may be ascribed to the effect of the structon ma- 
trix (third and fourth terms on the right in eq. (4.23)).

In fig. 2 see how the basicity of the structon matrix is affected by the value of the polymerisation constant, which dictates the structons contribution to the basicity of the medium.

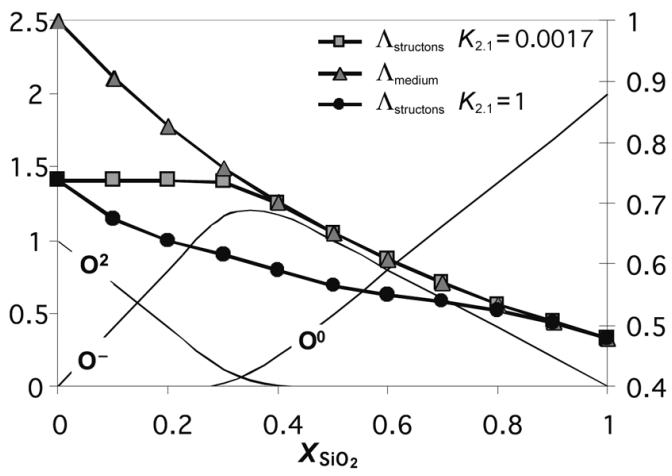

Fig. 2. Basicity of the medium and of the structon matrix (ordinate right-axis) calculated along the binary join $\mathrm{CaO}-\mathrm{SiO}_{2}$ assuming $\Lambda_{\mathrm{CaO}}=1$ and $K_{2.1}=0.0017$ (Toop and Samis, 1962a) and $K_{2.1}=1$ (guess value put for comparison). Abundances of quasi-chemical species of oxygen (ordinate left-axis) are shown as a function of the molar fraction of $\mathrm{SiO}_{2}$.
Moles of quasi-chemical species of oxygen are also shown for comparison.

Table III lists structural details along the join $\mathrm{CaO}-\mathrm{SiO}_{2}$, calculated adopting $K_{2.1}=0.0017$ (Toop and Samis, 1962a) and $\Lambda_{\mathrm{MO}}=1.00$ (Duffy and Ingram, 1974b). We may note that the bulk optical basicity of the medium is identical to that obtainable through direct application of eq. (4.19). However, note also that the bulk basicity of the medium may be entirely ascribed to the structon matrix over most part of the compositional join (for $X_{\mathrm{SiO}_{2}}>1 / 3$ ). The basicity control operated by the structon matrix is the more extended the more the dissolved oxide in the binary $\mathrm{MO}-\mathrm{SiO}_{2}$ system is basic (in the Lux-Flood acceptation of the term) and the lower the polymerisation constant $K_{2.1}$.

We have seen that in solving the various mass balances for different values of the polymerisation constant, Toop and Samis (1962a,b) showed that the Fincham and Richardson assumption of a purely anionic contribution to the Gibbs free energy of mixing in binaries $\mathrm{MO}-\mathrm{SiO}_{2}$ (with $\mathrm{MO}$ completely dissociated basic oxide) holds true.

It must be noted that the Toop-Samis model accounts for (negative) chemical interactions only and is not able to reproduce the experimentally observed solvi at high silica content even in simple systems. This implies additional excess Gibbs free energy terms of mixing which are not

Table III. Basicity of structons and basicity of the medium in the $\mathrm{MO}-\mathrm{SiO}_{2}$ binary ( $\mathrm{MO}$ is $\mathrm{CaO}$ ). $\Lambda_{\mathrm{MO}}=1$, $K p=0.0017$.

\begin{tabular}{cccccc}
\hline \hline$N_{\mathrm{SiO}_{2}}$ & $\mathrm{O}\langle 0\rangle$ & $\mathrm{O}\langle-\mathrm{I}\rangle$ & $\mathrm{O}^{2-}$ & $\Lambda_{\text {structons }}$ & $\Lambda_{\text {medium }}$ \\
\hline 0.000 & 0.000 & 0.000 & 1.000 & 0.739 & 1.000 \\
0.100 & 0.000 & 0.399 & 0.700 & 0.739 & 0.905 \\
0.200 & 0.003 & 0.795 & 0.403 & 0.738 & 0.826 \\
0.300 & 0.019 & 1.162 & 0.119 & 0.735 & 0.759 \\
0.400 & 0.211 & 1.178 & 0.011 & 0.700 & 0.702 \\
0.500 & 0.503 & 0.993 & 0.003 & 0.652 & 0.652 \\
0.600 & 0.801 & 0.797 & 0.001 & 0.609 & 0.609 \\
0.700 & 1.101 & 0.599 & 0.001 & 0.570 & 0.571 \\
0.800 & 1.400 & 0.400 & 0.000 & 0.536 & 0.536 \\
0.900 & 1.700 & 0.200 & 0.000 & 0.506 & 0.506 \\
1.000 & 2.000 & 0.000 & 0.000 & 0.478 & 0.478 \\
\hline
\end{tabular}


accounted by the model itself, as shown by Ottonello (2001). These additional terms (mechanical strain) are much smaller than chemical interaction, but are sufficient to open solvi at high silica content (Ottonello, 2001, 2005; Ottonello and Moretti, 2004). Nevertheless, the mechanical strain energy contribution is so low that eqs. (2.1) and (2.8) may be used by Ottonello et al. (2001) to infer appropriate values of the polymerisation constant $K_{2.1}$ in $\mathrm{MO}-\mathrm{SiO}_{2}$ systems from measured thermodynamic activities or Gibbs free energy of mixing (fig. 3 and Ottonello and Moretti, 2004).

A simple $T$-independent exponential relationship linking the polymerisation constant $K_{2}$ and the basicity moderating parameter of the dissolved cation, based on the estimates of Toop and Samis (1962a,b), Hess (1971), Reyes and Gaskell (1983), Masson et al. (1970) on binary $\mathrm{MO}-\mathrm{SiO}_{2}$ melts has been proposed by Ottonello et al. (2001)

$$
\gamma_{\mathrm{M}^{v+}}=\gamma_{\mathrm{M}^{v+}}+\frac{\ln K_{2.1}+1.1445}{4.662}\left(R^{2}=0.997\right)
$$

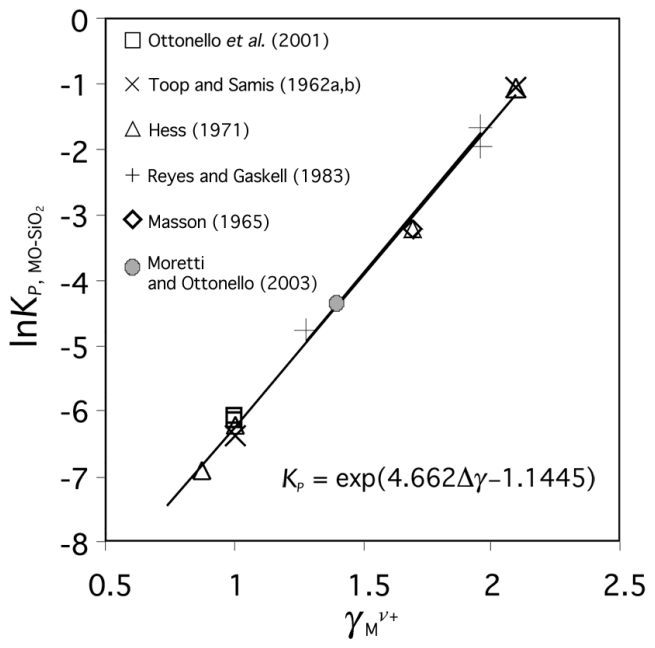

Fig. 3. Linear relationship between logarithm of the constant of polymerization reaction (2.1) in MO$\mathrm{SiO}_{2}$ melts and basicity moderating parameter of the network modifier $\mathrm{M}^{v+} . \Delta \gamma=\gamma_{\mathrm{M}^{2+}}-\gamma_{\mathrm{Si}^{4+}}$.

$$
\begin{aligned}
& K_{2.1, \mathrm{MO}-\mathrm{SiO}_{2}}=4 \times 10^{-5} \exp \left(3.8452 \gamma_{\mathrm{M}^{v+}}\right) \\
& \left(R^{2}=0.926\right) .
\end{aligned}
$$

Since, according to eq. (4.18), the Jorgensen $h$ function is a generalised property, accepting the validity of the above discussed relationship which links $\Delta \gamma$ and $K_{2.1}$ in simple systems, the extent of polymerisation of chemically complex melts and glasses may be readily obtained by a simple mass balance involving oxide constituents and their specific $\gamma$ values (Ottonello et al., 2001)

$$
\begin{aligned}
& K_{2.1, \text { melt }}=\exp \left[4.662 \times\left(\sum_{\mathrm{i}} X_{\mathrm{M}_{i}^{v^{+}}} \boldsymbol{\gamma}_{\mathrm{M}_{i}^{v^{+}}}+\right.\right. \\
& \left.\left.-\sum_{\mathrm{j}} X_{T_{j}^{\eta+}} \gamma_{T_{j}^{\eta+}}^{\eta^{+}}\right)-1.1445\right]
\end{aligned}
$$

where $X_{\mathrm{M}_{i}^{v^{+}}} \boldsymbol{\gamma}_{\mathrm{M}_{i}^{v^{+}}}$and $X_{T_{j}^{\eta+}} \boldsymbol{\gamma}_{T_{j}^{\eta+}}$ are respectively atom fraction and basicity moderating parameter of network modifiers and network formers in one mole of the multicomponent melt or slag.

We thus have a formal link between acidbase properties of the medium (expressed as a «contrast» between formers and modifier basicities) and polymerisation constants.

This equation represents a high $T$ approximation, polymerisation constants on single binaries being defined at a unique $T$ for each binary (see table 1 in Ottonello et al., 2001). More precise formulations in the multicomponent space are in progress, based on new $T$-dependent parameterisations of polymerisation in binary joins (Ottonello and Moretti, 2004).

Let us furnish now more details about the calculation of the anionic structure of the melt.

To estimate $K_{2.1}$ for the various binaries, Hess (1971) adopted Temkin's model for fused salts, which ascribes the thermodynamic activity of the molten oxide to the activity product of ionic fractions over cationic and anionic matrixes, i.e.

$$
a_{M O}=\left[\mathrm{M}^{\mathrm{v}+}\right]\left[\mathrm{O}^{2-}\right]=\frac{\left(\mathrm{M}^{\mathrm{v}+}\right)}{\sum \text { cations }} \times \frac{\left(\mathrm{O}^{2-}\right)}{\sum \text { anions }}
$$

where terms in brackets denote activities and terms in parentheses number of moles. 
Since in a $\mathrm{MO}-\mathrm{SiO}_{2}$ melt

$$
\left(\mathrm{M}^{\mathrm{v}+}\right) \equiv \sum \text { cations }
$$

and since the number of moles of $\mathrm{O}^{2-}$ in the melt is related to $K_{2.1}$ and $N_{\mathrm{SiO}_{2}}$ by mass balance (eqs. (2.4), (2.5) and (2.8)), the evaluation of $a_{M O}$ rests solely on the estimate of the number of structons present in the anion matrix

$$
\begin{gathered}
\sum \text { anions }=\left(\mathrm{O}^{2-}\right)+\sum \text { structons } \\
a_{\mathrm{MO}}=\frac{\left(\mathrm{O}^{2-}\right)}{\left[\left(\mathrm{O}^{2-}\right)+\sum \text { structons }\right]} .
\end{gathered}
$$

To evaluate $\sum$ structons, Hess (1971) followed the method devised by Flory (1953)

$$
\begin{aligned}
& \sum \text { structons }=\sum_{x=1}^{n} N_{\mathrm{Si}}\left[\frac{\left(1-P_{\langle 0\rangle}\right)^{2} P_{\langle 0\rangle}^{\mathrm{x}}\left(1-P_{\langle 0\rangle}\right)^{2 \mathrm{x}}}{P_{\langle 0\rangle}}\right] . \\
& {\left[\frac{4\left(3 \bar{\nu}_{\mathrm{Si}}\right) !}{\left(2 \bar{\nu}_{\mathrm{Si}}+2\right) ! \bar{\nu} !}\right]}
\end{aligned}
$$

where $N_{\mathrm{Si}}$ are the moles of silicon in the melt, $\bar{v}$ is the number of silicon atoms in the structon of and $P\langle 0\rangle$ is the fraction of silicon bonds that link to doubly bonded oxygens, i.e.

$$
P_{\langle 0\rangle}=\frac{2(\mathrm{O}\langle 0\rangle)}{[2(\mathrm{O}\langle 0\rangle)+(\mathrm{O}\langle-I\rangle)]} .
$$

Being $\bar{v}$ dependent on composition in a complex fashion, eq. (4.32) cannot be easily adapted to multicomponent melts.

To address the problem quantitatively we must know the acid-base behavior of each dissolved oxide (i.e. the disproportionation between «network formers» and «network modifiers») in order to consider the effect of mixing of both cationic and anionic constituents over the two sulblattices of interest (the activity of the generic oxide MO being now the bulk of eq. (4.27)).

To solve the problem Toop and Samis (1962a,b) proposed a «polymerisation path» of general validity, based essentially on the viscosity data of Bockris et al. (1955). As shown by Ottonello (1983), the polymerization path of the Toop-Samis model may be reconducted to the simple form

$$
\sum \text { structons }=\frac{N_{T}}{\bar{v}}
$$

where the simple power function

$$
\bar{v}=P_{\langle-1\rangle}^{-1.95}
$$

accounts for the mean number of tetrahedrally coordinated cation per structon, $P_{\langle-\mathrm{I}\rangle}$ is the proportion of singly bonded oxygen

$$
P_{\langle-\mathrm{I}\rangle}=\frac{(\mathrm{O}\langle-\mathrm{I}\rangle)}{\left[(\mathrm{O}\langle 0\rangle)+(\mathrm{O}\langle-\mathrm{I}\rangle)+N_{T}\right]}
$$

and accounts for the presence of charge-balanced tetrahedrally coordinated cations other than Si (see Ottonello, 1983, for details), i.e. $N_{T}=N_{\mathrm{Si}}+N_{\mathrm{Al}}+N_{\mathrm{FeIII}}$.

Equations (4.32) and (4.34) lead to consistent results, in terms of $K_{2.1}$ when applied to $\mathrm{MO}-\mathrm{SiO}_{2}$ melts. However it has been shown by Ottonello (1983) that the polymerisation path in chemically complex immiscible liquid portions (Watson, 1976; Ryerson and Hess, 1978, 1980) is better represented by the exponential form

$$
\bar{v}=\exp \left(-5 \ln P_{\langle I\rangle}^{\prime}-2.67\right) \text {. }
$$

The amount of experimental data is at presentday large enough to allow a re-estimation of the above parameters. Through non linear minimisation techniques we obtained

$$
v=(\exp 2.8776) \times P_{(-)}^{-1.7165} .
$$

Such a form allows us to define the extension of the anion matrix in the Toop-Samis framework along a unique polymerisation path.

The generalisations made for complex melts through eqs. (4.27), (4.28), (4.34), (4.36) and (4.38), together with eq. (4.17) and the ToopSamis equations constitute the polymeric model.

Deconvolution of the investigated systems into network formers and network modifiers was carried out by (Ottonello et al., 2001) assuming amphotheric behaviour for $\mathrm{Al}_{2} \mathrm{O}_{3}$ and $\mathrm{Fe}_{2} \mathrm{O}_{3}$ : i.e. $\mathrm{Al}^{3+}$ and $\mathrm{Fe}^{3+}$ are considered to have a partly acidic behaviour. They are network formers if counterbalanced by basic oxides such as $\mathrm{H}_{2} \mathrm{O}$, 
$\mathrm{Na}_{2} \mathrm{O}, \mathrm{K}_{2} \mathrm{O}$ and $\mathrm{CaO}$, to form complexes of the type $\mathrm{MAl}^{4+}, \mathrm{MFe}^{4+}$ or $\mathrm{M}_{0.5} \mathrm{Al}^{4+}, \mathrm{M}_{0.5} \mathrm{Fe}^{4+}$ which polymerise as $\mathrm{SiO}_{4}{ }^{4+}$ does. A completely acidic behaviour was assigned to $\mathrm{P}^{5+}$ while $\mathrm{Ti}^{4+}$ is treated as a network modifier, in agreement with new experimental observations (see later on) and with findings based on quantum chemistry argumentation applied to glass clusters (Kowada et al., 1995). A more precise definition of the LuxFlood character of the various oxides was later achieved by Ottonello and Moretti (2004) based on the conversion of the Pelton and Blander (1986) quasi-chemical parameterisation of binary $\mathrm{MO}-\mathrm{SiO}_{2}$ interactions to the Hybrid Polymeric Model. The new classification does not substantially alter the preceding observations.

On the basis of the above considerations, we may now address the problem of reactivity of altervalent oxides (i.e. those oxides which do disproportionate into different valent states and have potentially distinct structural roles) on a thermochemical basis.

\section{Factors controlling the $\mathrm{Fe}^{\mathrm{II}} / \mathrm{Fe}^{\mathrm{III}}$ ratio in silicate melts}

Since iron is the main redox buffer in natural silicate melts, the treatment is specifically developed for this element. Equilibrium among dissolved iron in glasses or melts, the anion matrix and the gaseous phase is usually written in the form (Johnston, 1964; Duffy, 1996)

$$
4 \mathrm{Fe}^{3+}{ }_{\text {(melt) }}+4 \mathrm{O}^{2-}{ }_{\text {(melt) }} \Longleftrightarrow 4 \mathrm{Fe}^{2+}{ }_{\text {(melt) }}+4 \mathrm{O}_{2 \text { (gas) }} \text {. }
$$

However, based on what was previously stated, this form is misleading since it confuses formal oxidation numbers with formal ionic charges. Let us assume that we have spectroscopic evidence that ferric iron is only present in polyanionic complexes, and that the octahedral coordination of $\mathrm{Fe}^{2+}$ observed in melts is the result of ionic couplings dictated by simple coulomb interactions. We will have in this case the bulk homogeneous equilibrium

$$
\begin{aligned}
& \mathrm{Fe}(\mathrm{III}) \mathrm{O}_{4 \text { (melt) }}^{5-}+\frac{7}{2} \mathrm{O}\langle 0\rangle_{\text {(melt) }}+\mathrm{e}^{-} \Longleftrightarrow \mathrm{Fe}_{\text {(melt) }}^{2+}+ \\
& +7 \mathrm{O}_{\text {(melt) }}^{-}+\frac{1}{2} \mathrm{O}^{2-}{ }_{\text {(melt) }}
\end{aligned}
$$

obtained summing up the partial equilibria

$$
\begin{gathered}
\mathrm{Fe} \text { (III) } \mathrm{O}_{4{ }_{(\text {melt }}^{5-}} \Longleftrightarrow \mathrm{Fe}^{3+}{ }_{\text {(melt) }}+4 \mathrm{O}^{2-}{ }_{\text {(melt) }} \\
\frac{1}{2} \mathrm{O}^{2-}{ }_{\text {(melt) }} \Longleftrightarrow \mathrm{e}^{-}+\frac{1}{4} \mathrm{O}_{2 \text { (gas) }} \\
\frac{7}{2} \mathrm{O}^{2-}{ }_{\text {(melt) }}+\frac{7}{2} \mathrm{O}\langle 0\rangle_{\text {(melt) }} \Longleftrightarrow 7 \mathrm{O}^{-}{ }_{\text {(melt) }} \\
\mathrm{Fe}^{3+}{ }_{\text {(melt) }}+\mathrm{e}^{-} \Longleftrightarrow \mathrm{Fe}^{2+}{ }_{\text {(melt) }}
\end{gathered}
$$

and the corresponding heterogeneous reaction

$$
\begin{aligned}
& \mathrm{Fe} \text { (III) } \mathrm{O}_{4}^{5-}{ }_{\text {(melt) }}+\frac{7}{2} \mathrm{O}\langle 0\rangle_{\text {(melt) }_{\text {m }}} \Longleftrightarrow \mathrm{Fe}^{2+}{ }_{\text {(melt) }}+ \\
& +7 \mathrm{O}^{-}{ }_{\text {(melt) }} \frac{1}{4} \mathrm{O}_{2 \text { (gas) }}
\end{aligned}
$$

Adopting the usual polymeric notation it may be easily seen that iron reduction induces depolymerisation of the melt structure

$$
\begin{aligned}
& \mathrm{Fe}(\mathrm{III}) \mathrm{O}_{4}^{5-}{ }_{\text {(melt) }}+\frac{7}{2} \mathrm{Si}_{2} \mathrm{O}_{7}^{6-}{ }_{\text {(melt) }}+\mathrm{e}^{-} \Longleftrightarrow \mathrm{Fe}^{2+}{ }_{\text {(melt) }}+ \\
& +7 \mathrm{SiO}_{4}^{4-}{ }_{\text {(melt) }}+\frac{1}{2} \mathrm{O}^{2-}{ }_{\text {(gas) }} \\
& \mathrm{Fe} \text { (III) } \mathrm{O}_{4{ }_{\text {(melt) }}^{5-}}^{5-}+\frac{7}{2} \mathrm{Si}_{2} \mathrm{O}_{7 \text { (melt) }}^{6-} \Longleftrightarrow \mathrm{Fe}^{2+}{ }_{\text {(melt) }}+ \\
& +7 \mathrm{SiO}_{4}^{4-}{ }_{\text {(melt) }}+\frac{1}{2} \mathrm{O}_{2 \text { (gas) }} .
\end{aligned}
$$

Let us now imagine that we have the spectroscopic evidence that ferrous iron form in the melt or glass true octahedral complexes (in the sense of Pauling, 1960). We could write the following homogeneous equilibria:

$$
\begin{aligned}
& \mathrm{Fe}(\mathrm{III}) \mathrm{O}_{4}^{5-}{ }_{\text {(melt) }}+4 \mathrm{O}\langle-\mathrm{I}\rangle_{\text {(melt) }}+\mathrm{e}^{-} \Longleftrightarrow \\
& \Longleftrightarrow \mathrm{Fe}(\mathrm{II}) \mathrm{O}_{6}^{10-}{ }_{\text {(melt) }}+2 \mathrm{O}\langle 0\rangle_{\text {(melt) }} \\
& \mathrm{Fe}(\mathrm{III}) \mathrm{O}_{4}^{5-}{ }_{\text {(melt) }}+5 \mathrm{O}\langle-\mathrm{I}\rangle_{\text {(melt) }}+\mathrm{e}^{-} \Longleftrightarrow \\
& \Longleftrightarrow \mathrm{Fe}(\mathrm{II}) \mathrm{O}_{6}^{10-}{ }_{\text {(melt) }}+\frac{5}{2} \mathrm{O}\langle 0\rangle_{\text {(melt) }}+\frac{1}{2} \mathrm{O}_{\text {(melt) }}^{2-} \\
& \mathrm{Fe}(\mathrm{III}) \mathrm{O}_{4}^{5-}{ }_{\text {(melt) }}+6 \mathrm{O}\langle-\mathrm{I}\rangle_{\text {(melt) }}+\mathrm{e}^{-} \Longleftrightarrow \\
& \Longleftrightarrow \mathrm{Fe}(\mathrm{II}) \mathrm{O}_{6}^{10-}{ }_{\text {(melt) }}+3 \mathrm{O}\langle 0\rangle_{\text {(melt) }}+\mathrm{O}_{\text {(melt) }}^{2-}
\end{aligned}
$$


or the corresponding heterogeneous reactions

$$
\begin{aligned}
& \mathrm{Fe}(\mathrm{III}) \mathrm{O}_{4}^{5-}{ }_{\text {(melt) }}+4 \mathrm{O}\langle-\mathrm{I}\rangle_{\text {(melt) }}+\frac{1}{2} \mathrm{O}^{2-} \Longleftrightarrow \\
& \Longleftrightarrow \mathrm{Fe}(\mathrm{II}) \mathrm{O}_{6}^{10-}{ }_{\text {(melt) }}+2 \mathrm{O}\langle 0\rangle_{\text {(melt) }}+\frac{1}{4} \mathrm{O}_{2 \text { (gas) }}
\end{aligned}
$$

$$
\begin{aligned}
& \mathrm{Fe}(\mathrm{III}) \mathrm{O}_{4}^{5-}{ }_{\text {(melt) }}+5 \mathrm{O}\langle-\mathrm{I}\rangle_{\text {(melt) }} \Longleftrightarrow \\
& \Longleftrightarrow \mathrm{Fe}(\mathrm{II}) \mathrm{O}_{6}^{10-}{ }_{\text {(melt) }}+\frac{5}{2} \mathrm{O}\langle 0\rangle_{\text {(melt) }}+\frac{1}{4} \mathrm{O}_{2 \text { (gas) }}
\end{aligned}
$$

$$
\mathrm{Fe}(\mathrm{III}) \mathrm{O}_{4}^{5-}{ }_{\text {(melt) }}+6 \mathrm{O}\langle-\mathrm{I}\rangle_{\text {(melt) }} \Longleftrightarrow \mathrm{Fe}(\mathrm{II}) \mathrm{O}_{6}^{10-}{ }_{\text {(melt) }}+
$$$$
+\frac{1}{2} \mathrm{O}^{2-}+3 \mathrm{O}\langle 0\rangle_{\text {(melt) }}+\frac{1}{4} \mathrm{O}_{2 \text { (gas) }} \text {. }
$$

The above notations emphasise the fact that we must now produce additional free oxygen ions $\mathrm{O}^{2-}$ by polymerisation steps

$$
\begin{aligned}
& \mathrm{Fe}(\mathrm{III}) \mathrm{O}_{4}^{5-}{ }_{\text {(melt) }}+5 \mathrm{SiO}_{4}^{4-}{ }_{\text {(melt) }}+\mathrm{e}^{-} \Longleftrightarrow \\
& \Longleftrightarrow \mathrm{Fe} \text { (II) } \mathrm{O}_{6}^{10-}{ }_{\text {(melt) }}+\frac{5}{2} \mathrm{Si}_{2} \mathrm{O}_{7 \text { (melt) }}^{6-}+\frac{1}{2} \mathrm{O}_{\text {(melt) }}^{2-}
\end{aligned}
$$

$$
\begin{aligned}
& \mathrm{Fe}(\mathrm{III}) \mathrm{O}_{4}^{5-}{ }_{\text {(melt) }}+5 \mathrm{SiO}_{4}^{4-}{ }_{\text {(melt) }} \Longleftrightarrow \\
& \Longleftrightarrow \mathrm{Fe}(\mathrm{II}) \mathrm{O}_{6}^{10-{ }_{\text {(melt) }}}+2 \mathrm{Si}_{2} \mathrm{O}_{7 \text { (melt) }}^{6-}+\frac{1}{4} \mathrm{O}_{2 \text { (gas) }} .
\end{aligned}
$$

The iron reduction may be regarded as an internally buffered auto catalytic reaction: production of free electrons through the normal oxygen electrode favours decomposition of ferric iron clusters, making iron ions available to reduction by free electrons. This is true regardless of the fact that octahedral iron clusters may be present as simple ionic couplings (eqs. (5.2) to (5.4)) or as true complexes (eqs. (5.11) to (5.17)). In both instances, the whole process is buffered by the availability of free oxygen in the melt, which ceases at a critical acidity limit, due to polymeric equilibria.

The fact that nominal $\mathrm{O}^{2-}$ may appear either as reactants or products stresses how misleading it could be to conceive the Le Chatelier principle in terms of the simple mass action effect of oxide ions. As noted by Douglas et al. (1966) the altervalent equilibria in melts and glasses may be generalised as follows:

$$
\begin{aligned}
& R(n) \mathrm{O}_{a}+\frac{m}{4} \mathrm{O}_{2} \Longleftrightarrow R(n+m) \mathrm{O}_{b}+ \\
& +\left[(a-b)+\frac{m}{2}\right] \mathrm{O}^{2-}
\end{aligned}
$$

Equilibria such as those proposed by Johnston (1964); or Duffy (1996), (eq. (4.38)) and apparently violating the Le Chatelier principle demand $b<(a+m / 2)$. If $b>(a+m / 2)$, such as in the Holmquist (1966) formulation

$$
\begin{aligned}
& 4 \mathrm{Fe}(\mathrm{III}) \mathrm{O}\langle-\mathrm{I}\rangle_{2 \text { (melt) }}^{-} \Longleftrightarrow 4 \mathrm{Fe}^{2+}{ }_{\text {(melt) }}+6 \mathrm{O}^{2-}{ }_{\text {(melt) }}+ \\
& +\mathrm{O}_{2 \text { (gas) }}
\end{aligned}
$$

there is no paradox, and when $b=(a+m / 2)$ the equilibrium is written in a simple stoichiometric form (i.e. no oxide ions involved)

$$
\mathrm{FeO}+\frac{1}{4} \mathrm{O}_{2} \Longleftrightarrow \mathrm{FeO}_{1.5} .
$$

In the above equations it is assumed that ferric iron behaves essentially as a network former, although we know that in chemically complex melts or glasses the structural behavior of $\mathrm{Fe}^{\mathrm{III}}$ is a complex function of both bulk composition and $\mathrm{Fe}^{\mathrm{III}}$ concentration.

This simply means that the above equation, written for macroscopic melt components, must be coupled with homogeneous speciation reactions defining the structural state of iron in melts and glasses (which is a function of bulk composition and $P, T$ conditions, as shown by experimental evidence). Mössbauer observations on quenched melts (Mysen, 1990, and references therein) indicate that when $\mathrm{Fe}^{\mathrm{III}}$ exceeds $\mathrm{Fe}^{\mathrm{II}}\left(\mathrm{Fe}^{\mathrm{III}} / \sum \mathrm{Fe} \geq 0.3\right)$ ferric iron is only present in tetrahedral clusters; for $0.5 \geq \mathrm{Fe}^{\mathrm{III}} / \Sigma \mathrm{Fe} \geq 0.3$ both tetrahedrally and octahedrally coordinated $\mathrm{Fe}^{\mathrm{III}}$ is present and for $\mathrm{Fe}^{\mathrm{III}} / \Sigma \mathrm{Fe} \leq 0.5$ tetrahedral clusters are absent. Virgo and Mysen (1985) on the basis of spectroscopic and magnetic data suggested that coexistence of $\mathrm{Fe}^{\mathrm{III}}$ and $\mathrm{Fe}^{\mathrm{II}}$ leads to formation of units stoichiometrically resembling $\mathrm{Fe}_{3} \mathrm{O}_{4}$ and composed of 0.33 tetrahedrally coordinated $\mathrm{Fe}^{\mathrm{III}}, 0.33$ octahedrally coordinated $\mathrm{Fe}^{\mathrm{III}}$ and 0.33 octahedrally coordinated $\mathrm{Fe}^{\mathrm{II}}$ (Virgo and Mysen, 1985). Experimental data on melt 
densities at various $T, f \mathrm{O}_{2}$ conditions seem to confirm that $\mathrm{Fe}^{\mathrm{III}}$ is essentially present in tetrahedral coordination, although some discrepancies in the partial molar volumes of molten $\mathrm{Fe}_{2} \mathrm{O}_{3}$ based on various experiments could be ascribed to the limited presence of a higher coordination state in some of the investigated materials (see Bottinga et al., 1983; Dingwell et al., 1988, and references therein).

The fact that $\mathrm{Fe}^{\mathrm{III}}$ could partly exist in octahedral coordination with oxygen may be ascribed to the partial reaction

$$
\begin{aligned}
& \mathrm{Fe}(\mathrm{III}) \mathrm{O}_{4{ }_{(\text {melt })}^{5-}}^{5}+5 \mathrm{O}\langle-\mathrm{I}\rangle \Longleftrightarrow \mathrm{Fe}(\mathrm{III}) \mathrm{O}_{6}^{9-}{ }_{\text {(melt) }}+ \\
& +\frac{5}{2} \mathrm{O}\langle 0\rangle_{\text {(melt) }}+\frac{1}{2} \mathrm{O}^{2-}{ }_{\text {(melt) }} .
\end{aligned}
$$

The above equilibria show us that the nature of bonding between central cations and ligands must be attentively evaluated before reaching unwarranted conclusions.

Although the compositional effect differs in the various investigated systems $\left(f \mathrm{O}_{2}\right.$ being held constant), Duffy $(1992,1996)$ has shown that the basicity effect is identical for all binary systems whenever optical basicity is introduced for the compositional axis. Duffy (1992) proposed, at $T=1400^{\circ} \mathrm{C}$, the following semilogarithmic relationship between the observed redox mass ratio of iron and optical basicity

$$
\log \left(\frac{\mathrm{Fe}^{\mathrm{II}}}{\mathrm{Fe}^{\mathrm{III}}}\right)=3.2-6.5 \Lambda \text {. }
$$

Although this relationship disregards the effect of temperature on the extent of the polymerisation reaction, it is sufficiently accurate to allow comparative estimates on widely differing systems.

Nevertheless, this kind of equation cannot be usefully employed on an empirical basis, not because of the chosen parametric scale (i.e. optical basicity) but rather because of the adopted functional form. Figure 4 shows that Duffy's reworked expression (see figure) does not reach a good accuracy in reproducing the $1400^{\circ} \mathrm{C}$ data available from the literature.

Following Fraser (1975, 1977), Ottonello et al. (2001) assumed that $\mathrm{Fe}_{2} \mathrm{O}_{3}$ behaves as an amphoteric oxide in the Lux-Flood acid-base acceptation. Its double dissociation in the melt (or glass) may be reconducted to the following homogeneous reactions:

$$
\begin{gathered}
\mathrm{Fe}_{2} \mathrm{O}_{3(\text { melt })}+\mathrm{O}^{2-}{ }_{\text {(melt) }} \Longleftrightarrow 2 \mathrm{Fe}(\mathrm{III}) \mathrm{O}\langle-\mathrm{I}\rangle_{2 \text { (melt) }} \\
\mathrm{Fe}_{2} \mathrm{O}_{3 \text { (melt) }} \Longleftrightarrow 2 \mathrm{Fe}^{3+}{ }_{\text {(melt) }}+3 \mathrm{O}^{2-}{ }_{\text {(melt) }} .
\end{gathered}
$$

For ferrous iron on the other hand only a basic dissociation is plausible, i.e.

$$
\mathrm{FeO}_{\text {(melt) }} \Longleftrightarrow \mathrm{Fe}^{2+}{ }_{\text {(melt) }}+\mathrm{O}^{2-}{ }_{\text {(melt) }} \text {. }
$$

Adopting the Temkin model for ionic salts (Temkin, 1945) and assuming the $\mathrm{Fe}(\mathrm{III}) \mathrm{O}\langle-\mathrm{I}\rangle_{2}$ clusters to mix ideally over the structon matrix and the $\mathrm{Fe}^{3+}, \mathrm{Fe}^{2+}$ cations to mix ideally over the cation matrix, after some passages one arrives at (Ottonello et al., 2001)

$$
\begin{aligned}
& \left(\frac{\mathrm{Fe}^{\mathrm{II}}}{\mathrm{Fe}^{\mathrm{III}}}\right)=\frac{1}{K_{5.20} a_{\mathrm{O}_{2}}^{1 / 4}} \times \\
& \times \frac{a_{\mathrm{O}^{2}-}^{1 / 2} K_{5.25} \sum \text { cations }}{K_{5.23}^{1 / 2} a_{0^{2-}}^{2}} \sum \text { anions }+K_{5.24}^{1 / 2} \sum \text { cations }
\end{aligned}
$$

which is analogous to eq. (14) in Fraser (1975),

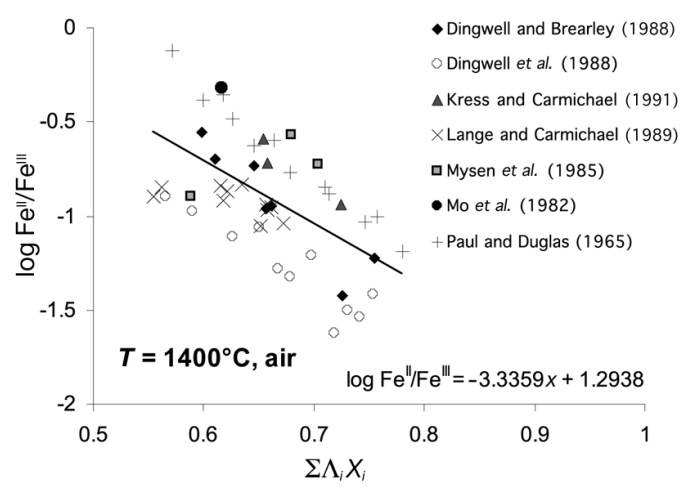

Fig. 4. Experimental ferrous to ferric iron ratio versus summation of oxide optical basicities. Data from various sources, also included in the database of Ottonello et al. (2001), show the need for a more rigorous approach to the functional form based on optical basicity. 
although here $\sum$ anions replaces, more correctly, $\sum$ structons, since free anions such as $\mathrm{O}^{2-}, \mathrm{CO}_{3}{ }^{2-}$, $\mathrm{S}^{2-}, \mathrm{SO}_{4}{ }^{2-}$ etc., are present in the anionic matrix, besides polymeric species.

Equation (5.26) implies that, due to disproportionation of trivalent iron between the cationic and anionic matrixes, we cannot expect the ratio of rational activity coefficients of $\mathrm{FeO}_{1.5}$ and $\mathrm{FeO}$ (second term on the right) to be 1. In fact the first term on the right side of eq. (5.26) represents $a_{\mathrm{FeO}} / a_{\mathrm{FeO}_{1.5}}$ (see eq. (5.20)), whereas the second term represents $\gamma_{\mathrm{FeO} 1.5} / \gamma_{\mathrm{FeO}}$.

If we compare eq. (5.26) with the functional form (5.22) we would deduce that the intercept term in the equation of Duffy (1992) corresponds to the first term on the right in eq. (5.26), whilst the slope coefficient embodies the remaining structural parameters.

Since the polymeric model allows the calculation of the extension of the structon and the cation matrixes, Ottonello et al. (2001) conveniently solved eq. (5.26) on thermochemical grounds, based on the plethora of experimental data concerning ferrous iron solubility and iron redox ratios in melts (and/or glasses) equilibrated at known $T$ and $f \mathrm{O}_{2}$ conditions. Nevertheless, this was done only for nominally anhydrous melts synthesised at 1 bar pressure. On this basis we can also investigate the dependence of iron oxidation state under hydrous conditions and therefore at higher pressure. It may be here anticipated that the way iron disproportionates also depends on water speciation in melts, as a consequence of the effect that water carries on polymerisation and then basicity in terms of free oxygen ions activity.

\section{Iron oxidation state in hydrous alumino- silicate melts: a preliminary model extension}

Water is commonly perceived as the most basic oxide: its presence in the natural systems undergoing melting dramatically affects the solidus temperature and the composition of the incipient melting liquid. Nevertheless, its basicity (in the Lux-Flood sense of the term) seems to be over rated, $\Lambda_{\mathrm{H}_{2} \mathrm{O}}$ being very close to $\Lambda_{\mathrm{SiO}_{2}}$ (table I). Therefore, it is of primary interest to test the model reproducibility at pressure and investigate how both polymerisation and the ferric to ferrous iron ratio in melts are affected. The still few data at present available in literature also involve the presence of water. Here I present an exploratory extension of the 1-bar anhydrous model of Ottonello et al. (2001).

First of all, it is necessary to introduce the effect of pressure on the equilibrium constants for reactions (5.20) and ((5.23) to (5.25)). This is easily done by accounting for volume terms of both ionic species and macroscopic compo-

Table IV. Molar volumes employed for macroscopic and ionic species involved in reactions (5.20), ((5.23) to $(5.25)),(6.3)$ and (6.12). For ionic species I also listed the the adopted ionic radius.

\begin{tabular}{cccc}
\hline \hline & $\begin{array}{c}\text { Molar Volume @ 298.15 K } \\
298.15 \mathrm{~K}(\mathrm{cc} / \mathrm{mol})\end{array}$ & $\begin{array}{c}\text { Ionic radius } \\
(\AA)\end{array}$ & Reference \\
\hline $\mathrm{FeO}$ & 9.64 & - & Lange (1994) \\
$\mathrm{Fe}_{2} \mathrm{O}_{3}$ & 29.63 & - & Lange (1994) \\
$\mathrm{Fe}^{2+}$ & 0.90 & 0.78 & Shannon (1976) \\
$\mathrm{Fe}^{3+}$ & 0.51 & 0.645 & Shannon (1976) \\
$\mathrm{O}^{2-}$ & 6.92 & 1.40 & Shannon (1976) \\
$\mathrm{FeO}_{2}^{-}$ & $75.99\left(^{*}\right)$ & $3.29\left(^{* *}\right)$ & Shannon (1976) \\
$\mathrm{OH}^{-}$ & 6.92 & 1.40 & Shannon (1976) \\
$\mathrm{OH}^{+}$ & 6.92 & 1.40 & Shannon (1976) \\
$\mathrm{H}^{+}$ & 0 & 0 & This work \\
\hline
\end{tabular}

(*) See text for details.

$\left(^{* *}\right)$ The value here adopted represents the summation of the radius of four-folded ferric iron $(0.49 \AA)$ and the diameter of an oxide ion $\mathrm{O}^{2-}$. 
nents. This procedure is consistent with the Temkin approach inherent in the Toop-Samis model, which demands scaling of the activities of liquid components from the standard state of pure melt components at $P$ and $T$ of interest to the standard state of completely dissociated ionic component.

The equilibrium constant for reaction (5.20), involving the macroscopic oxides $\mathrm{FeO}$ and $\mathrm{FeO}_{1.5}$ is then recomputed as

$$
\begin{aligned}
& \ln K_{5.20(P, T)}=\ln K_{5.20(1, T)}-\frac{1}{R T} \int_{1}^{P} \Delta V_{\text {melt }}^{\circ} d P+ \\
& +\frac{1}{4 R T} \int_{1}^{P} V_{\mathrm{O}_{2, \text { gas }}}^{\circ} d P
\end{aligned}
$$

where

$$
\int_{1}^{\mathrm{P}} \Delta V_{\text {melt }}^{\circ} d P=\int_{1}^{\mathrm{P}}\left(V_{\mathrm{FeO}_{1.5}, \mathrm{melt}}^{\circ}-V_{\mathrm{FeO}, \mathrm{melt}}^{\circ}\right) d P .
$$

Molar volumes of melt phases, as well as isothermal compressibilities and isobaric thermal expansivities have been taken by Lange (1994).

For reactions (5.23) to (5.25) I still consider the Lange (1994) data for macroscopic oxides $\mathrm{Fe}_{2} \mathrm{O}_{3}$ and $\mathrm{FeO}$, whereas volume of ionic species are calculated on the basis of ionic radii of Shannon (1976) assuming that the "effective molar volume' of each ionic species equals that of a mole of spherical molecules each characterised by its appropriate Shannon radius. Note that for $\mathrm{FeO}_{2}^{-}$species I calculated the molar volume from that of a sphere of radius $r_{\mathrm{O}^{2-}}+(1 / 2) r_{\mathrm{Fe}^{3+}(\mathrm{IV})}$. Since the spherical volume associated with this radius should represent, at a first approximation, the 'effective volume' of the $\mathrm{Fe}^{\mathrm{III}} \mathrm{O}_{4}{ }^{5-}$ complex, I subtracted the volume of two oxide ions $\mathrm{O}^{2-}$ in order to obtain the "effective volume' of the $\mathrm{FeO}_{2}{ }^{-}$compound. This means that I assume the volume change reaction for the association reaction $\mathrm{FeO}_{2}^{-}+2 \mathrm{O}^{2-} \Longleftrightarrow \mathrm{FeO}_{4}^{5-}$ to be zero.

Values of employed volumes are listed in table IV.

In our calculation the ionic radius for each ionic species is fixed for all temperatures (i.e. thermal expansivity is zero), therefore I recalculated the thermal expansivity of macroscopic oxides at $298.15 \mathrm{~K}$, obtaining that the variation in the reaction volume change is a constant at any temperature.

The model is now ready to investigate the role played by water in the ferric to ferrous iron ratio of melts. Data in the literature disclose some controversies about the oxidation state of iron under hydrous conditions. Following Moore et al. (1995), water does not affect the ferric to ferrous iron ratio, which is a record of other processes having imposed the oxygen fugacity.

According to Baker and Rutherford (1996) and Gaillard et al. (2001) water does affect the ferric to ferrous ratio. In some region of the $P$ $T-f \mathrm{O}_{2}$ space it may cause either a decrease or an increase of oxidation. For example water-bearing rhyolitic melts have higher ferric to ferrous ratio than anhydrous melts of the same composition (Baker and Rutherford, 1996). The same occurs in metaluminous melts, but at higher temperatures $\left(T>900^{\circ} \mathrm{C}\right)$ and around $\mathrm{NNO}$, whereas in peralkaline melts such an increase is observed at high $T$ (Baker and Rutherford, 1996). Gaillard et al. (2001) generalise this perspective, observing an increase in the ferric to ferrous ratio of iron in hydrous melts at $\log f \mathrm{O}_{2}<$ $<\mathrm{NNO}+1.5$ for all studies compositions, metaluminous and rhyolitic melts and natural peraluminous and peralkaline obsidians. However they find that above $\mathrm{NNO}+1.5$ water does no longer affects the ferric to ferrous iron ratio, controlled by the anhydrous composition in agreement with Moore et al. (1995). Finally, Wilke et al. (2002) investigated tonalitic melts at $850^{\circ} \mathrm{C}$, whose ferric to ferrous iron ratio showed a marked decrease with respect to the values computed through the Kress and Carmichael (1991) and then based on the anhydrous composition. Nevertheless, this effect is mainly ascribed to the inaccurate calibration of the Kress-Carmichael equation at low $T$ rather than to the water content of melts.

It is important to remark that Wilke et al. (2002) and Gaillard et al. (2001) did not observe any effect of the quench rate on the ferric to ferrous ratio of investigated melts. This conclusion cannot be obviously extended to the re- 
maining data here discussed, so quench-rate effects may still represent an important source of uncertainty.

Moreover, the dependencies of the ferric to ferrous iron ration on water amount are contrasting: Baker and Rutherford (1996) find different explanations about the role of hydroxyl groups (Baker and Rutherford, 1996), whose complexity is enriched by the $T$ dependency of water speciation (between $\mathrm{OH}^{-}$and $\mathrm{H}_{2} \mathrm{O}$ for all the authors observing change on the iron oxidation state with the water content).

These experimental results are likely to show only apparent controversies. I then considered the database generated by these authors (119 compositions) in order to expand the model of Ottonello et al. (2001). It is clear that the parameterisation of the ferric to ferrous ratio must consider the «impact» of water on melt acid-base properties and then polymerisation. In order to match this goal in the widest available $P-T-X$ range, I also considered thirty-seven 1 bar compositions (from Fudali, 1965; and Shibata, 1967) showing some water content (up to $0.66 \mathrm{wt} \%$ ) and which were already accounted for by Ottonello et al. (2001).

Consistent with the Temkin formalism of complete dissociation of component oxides and on the basis of that «common perception» which requires water to behave as a strong modifier (being a strong basic oxide in the LuxFlood notation), I first considered water as undergoing uniquely a basic dissociation

$$
\mathrm{H}_{2} \mathrm{O} \Longleftrightarrow 2 \mathrm{H}^{+}+\mathrm{O}^{2-} \text {. }
$$

Let us recall that this kind of dissociation is accompanied by other homogeneous reactions in the melt phase (Fraser, 1975; Ottonello, 1997), i.e. the association to NBOs' originating strong hydrogen bonding, and the polymerisation reaction (6.4)

$$
\begin{gathered}
2 \mathrm{H}^{+}+2 \mathrm{O}^{-} \Longleftrightarrow 2 \mathrm{OH} \\
\mathrm{O}^{2-}+\mathrm{O}^{0} \Longleftrightarrow 2 \mathrm{O}^{-} .
\end{gathered}
$$

The summation of eqs. (6.2), (6.3) and (6.4) gives

$$
\mathrm{H}_{2} \mathrm{O}+\mathrm{O}^{0} \Longleftrightarrow 2 \mathrm{OH}
$$

which well displays the depolymerising effect of water and which has been first discussed by Fraser $(1975,1977)$.

According to the Temkin notation of complete dissociation, implicit in the Toop-Samis approach, all the protons were considered to contribute in defining the basicity of modifiers (i.e. the basicity of the cationic matrix). The polymeric constant and then initial $\left(\mathrm{O}^{-}\right)$values were computed assuming only the occurrence of reaction (6.2), without any concomitant equilibrium (i.e. eq. (6.3)) leading to bonding with NBO's. The latter mechanism was considered as a subsequent step involving depletion of both initial $\mathrm{O}^{-}$and $\mathrm{H}^{+}$to form $\mathrm{OH}$. The following mass balances must be satisfied:

$$
\begin{gathered}
n_{\mathrm{O}^{-}}=n_{\mathrm{O}^{-}}^{\mathrm{IN}}-n_{\mathrm{OH}} \\
n_{\mathrm{H}^{+}}=n_{\mathrm{H}^{+}}^{\mathrm{IN}}-n_{\mathrm{OH}} .
\end{gathered}
$$

The equilibrium constant for reaction (6.3) may be expressed as

$$
K_{6.3}^{1 / 2}=\frac{n_{\mathrm{OH}}}{n_{0^{-}}} \cdot \frac{\sum \text { cations }}{n_{\mathrm{H}^{+}}} .
$$

With some passages, substitution of eqs. (6.6) and ((6.7) to (6.8)) gives the following quadratic equation:

$$
\begin{aligned}
& K_{6.3}^{1 / 2} \cdot n_{\mathrm{OH}}^{2}-\left(K_{6.3}^{1 / 2} \cdot n_{\mathrm{H}^{+}}^{\mathrm{IN}}+K_{6.3}^{1 / 2} \cdot n_{0^{-}}^{\mathrm{IN}}+\sum \text { cations }\right) \\
& \cdot n_{\mathrm{OH}}+K_{6.3}^{1 / 2} \cdot n_{\mathrm{H}^{+}}^{\mathrm{IN}} \cdot n_{\mathrm{O}^{-}}^{\mathrm{IN}}=0 .
\end{aligned}
$$

The equation above has two possible roots, but only the following one provides solutions falling between initial $\mathrm{O}^{-}$and initial $\mathrm{H}^{+}$, and then physically meaningful

$n_{\mathrm{OH}}=\frac{K_{6.3}^{1 / 2} \cdot n_{\mathrm{H}^{+}}^{\mathrm{IN}}+K_{6.3}^{1 / 2} \cdot n_{\mathrm{O}^{-}}^{\mathrm{N}}+\sum \text { cations }+}{}$

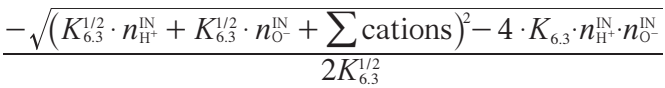

$\left(\mathrm{O}^{2-}\right),\left(\mathrm{O}^{0}\right), \sum$ structons were then recalculated on the basis of the new $\mathrm{O}^{-}$values. The number of newly formed $\mathrm{OH}$ groups, $n_{\mathrm{OH}}$, was then included in the quantity $\sum$ anions. 
Furthermore, we should also consider that the theory, based on the Lux-Flood formalism, gives us an alternative to be evaluated: the amphoteric behavior of water, i.e. the existence of an acidic dissociation, as testified by its relatively low value of optical basicity. The following reaction:

$$
\mathrm{H}_{2} \mathrm{O}+\mathrm{O}^{2-} \Longleftrightarrow 2 \mathrm{OH}^{-}
$$

was first proposed by Fraser (1975). Moreover the existence of free $\mathrm{OH}^{-}$has recently been reported by Xue and Kanzaky (2003). Reaction (6.11) is actually that normally invoked in literature to explain water dissolution in aluminosilicate melts. Nevertheless, in the literature it is not regarded as an acidic dissolution mechanism, neglecting the fact that it leads to melt polymerisation because of the consumption of free oxygens.

I then introduced in the model the difference between reaction (6.11) and reaction (6.2), i.e.

$$
\mathrm{H}^{+}+\mathrm{O}^{2-} \Longleftrightarrow \mathrm{OH}^{-}
$$

whose equilibrium constant may be written as

$$
K_{6.12}=\frac{n_{\mathrm{OH}^{-}}}{n_{\mathrm{O}^{2-}}} \cdot \frac{\sum \text { cations }}{n_{\mathrm{H}^{+}}^{\mathrm{TOT}^{+}}-n_{\mathrm{OH}^{-}}} .
$$

This equation simply recognises the existence of two dissolved species of water in melts, i.e. $\mathrm{OH}^{-}$and $\mathrm{H}^{+}$, consistently with the Temkin formalism and the Lux-Flood notation for oxide solvents.

I therefore by-pass the problem of determining the activity of water in melts as well as in the fluid phase, a problem which would be posed by solving eqs. (6.2) and (6.11) separately or by solving their algebraic sum. The system of equations is simply solved through additional mass balance on water

$$
n_{\mathrm{H}^{+}}^{\mathrm{IN}}+n_{\mathrm{OH}^{-}}=2 \cdot n_{\mathrm{H}_{2} \mathrm{O}}
$$

and the equilibrium constant for water speciation reaction (6.12). Equation (6.10) partitions the initial water amount, so that $K_{2.1 \text {,polymerisation }}$ is no more defined on the total analytical water content.
Regression on available experimental data is performed through non-linear minimisation techniques based on steepest descent and gradient migration methods (James and Roos, 1977) on both $K_{6.3}^{1 / 2}$ and $K_{6.12}$. Equilibrium constants values and statistics for the extended iron model are given in table $\mathrm{V}$, whereas reproducibility may be appreciated in fig. 5. It is worth remarking that the $T$ dependence obtained for equilibrium (6.12) shows that this reaction becomes more important at higher $T$. On the other hand, reaction (6.3) is independent of temperature (the entropic term of the arrhenian dependence

Table V. Equilibrium constants for water speciation mechanisms and model statistics.

\begin{tabular}{ll}
\hline \hline $\log K_{6.12}$ & $1.835-1304.65 / T$ \\
$1 / 2\left(\log K_{6.3}\right)$ & -1.335 \\
$\begin{array}{l}\text { Number of hydrous } \\
\text { compositions }\end{array}$ & 120 \\
$\begin{array}{l}\text { Number of all compositions } \\
\text { (anhydrous+hydrous) }\end{array}$ & 608 \\
$\begin{array}{l}\text { Mean error (hydrous dataset) } \\
\begin{array}{l}\text { Standard error } \\
\text { (hydrous dataset) }\end{array}\end{array}$ & 0.277 \\
$\begin{array}{l}\text { Mean error (whole dataset) } \\
\text { Standard error (whole dataset) }\end{array}$ & 0.357 \\
\hline
\end{tabular}

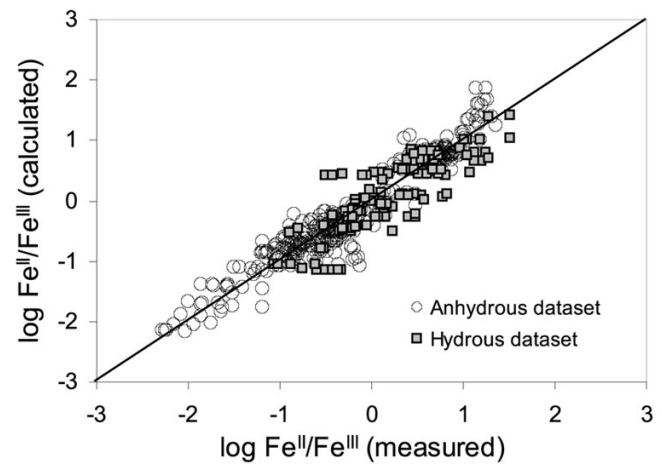

Fig. 5. Reproduciblity (calculated versus experimental) of the extended iron oxidation state model. Anhydrous and hydrous datasets are distinguished. The whole database consists of 608 compositions. 
describes the equilibrium constant) and leftward shifted.

The effect of pressure was neglected for reactions involving water species as the volume associated with $\mathrm{H}^{+}$was assumed to be zero, so that $V_{\mathrm{O}^{2}}=V_{\mathrm{OH}^{-}}=V_{\mathrm{OH}}$.

The comparatively low precision of the hydrous dataset with respect to the anhydrous one probably reflects model approximations, similarly to what was described for sulphur speciation in Moretti and Ottonello (2003a). In particular, a more general model based on the assessment of water solubility and speciation should require the Flood-Grjotheim treatment (Flood and Grjotheim, 1952) opportunely implemented and already used for sulphur species (Moretti, 2002; Moretti and Ottonello, 2003b). Moreover, more accurate data for molar partial volumes are needed, in particular for iron oxides. In principle, we could improve the precision of our model by refining on volume reactions, but I prefer to employ independent experimental volume data. A possible source of error is also related to the $T$-independent computation of the polymeric extension of the anionic matrix: a more general, i.e. $T$ dependent (Ottonello and Moretti, 2004, and work in progress) polymerisation equation would represent a step forward in the continuos attempt to ameliorate model results and applications.

Figure 6a,b shows a comparison between: i) equation (5.26), accounting for water speciation and volume terms; ii) equation (5.26) under the 1 bar approximation and without considering eqs. (6.3) and (6.12); and iii) the Kress and Carmichael (1991) empirical model.

It is evident that both eq. (5.26) under the 1 bar approximation and the Kress-Carmichael algorithm do not work well in reproducing the observed $\mathrm{Fe}^{\mathrm{II}} / \mathrm{Fe}^{\mathrm{III}}$ ratio, which is largely underestimated in the first case.

It is important to remark that the fact that we «identify» three water-derived species in melts $\left(\mathrm{H}^{+}\right.$cations, $\mathrm{OH}^{-}$free anions and, to a very minor extent, $\mathrm{OH}$ groups terminating polymeric units, which can be then ascribed to T-OH linkages) is quite consistent with NMR findings (Kohn et al., 1989; Schmidt, 2001; Xue and Kanzaki, 2003). Intuitively, it would seem that their combination reproduces the water speciation - and solubility - observed in melts, simi-
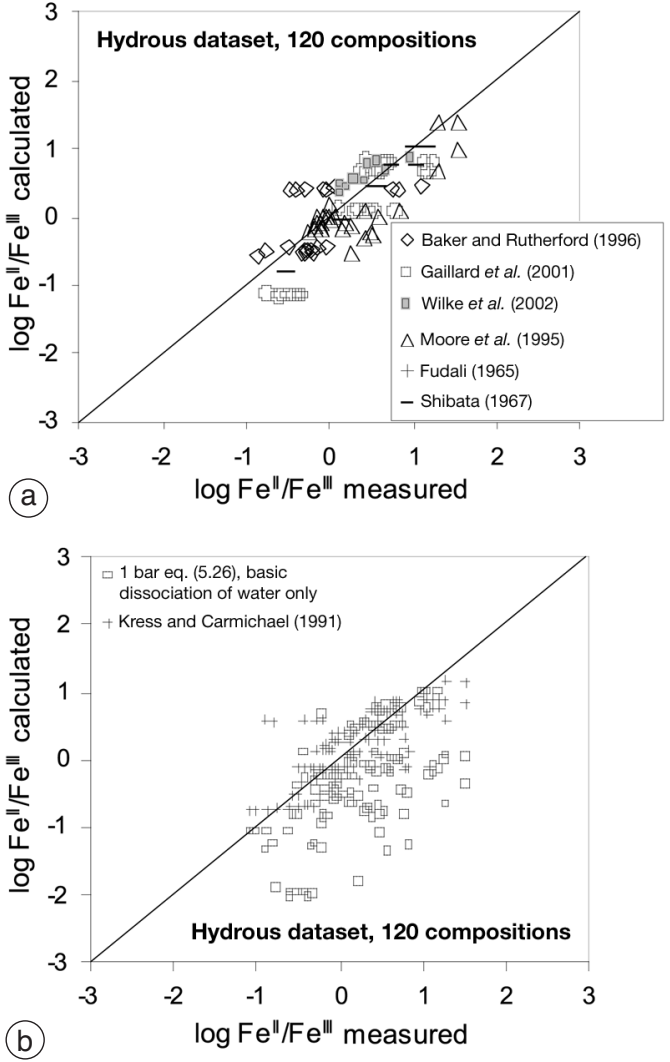

Fig. 6a,b. Model reproducibility of the hydrous datasets following different approaches (see text). In part a) of the figures data from various sources have been distinguished. $\mathrm{H}_{2} \mathrm{O}$-unsaturated data from Baker and Rutherford (1996) were not considered.

larly to what was argued by Liu et al. (2002). Nevertheless these arguments cannot be pushed further and are purely qualitative: the model here developed is not aimed at reproducing the speciation observed via FTIR or NMR since model computations are based on a particular standard state (that of completely dissociated component) which is introduced to describe the acid-base properties of melts and not the structural units detected by spectroscopic tools. For example, the existence of equilibrium (6.2) and (6.11) (and hence equilibrium (6.12)) implies incomplete dissociation of the water component 

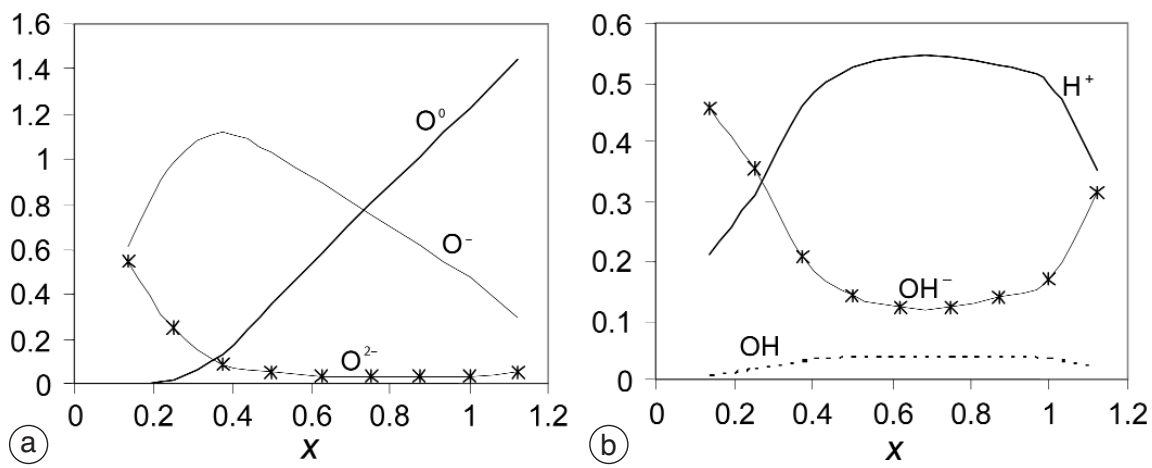

Fig. 7a,b. Relative proportions of oxygens of the Fincham-Richardson (1954) notation (a) plotted against the compositional parameter in the binary join $\mathrm{Na}_{5-4 x} \mathrm{Al}_{x} \mathrm{Si}_{3 x} \mathrm{O}_{8}$. Water-derived species dissolved in the same compositional range have been plotted in $\mathrm{b}$ ). Note the comparable amount of $\mathrm{OH}$ and $\mathrm{OH}^{-}$for the albitic composition $(x=1)$.

and therefore the presence of molecular water. The existence of this species is not ruled out by the present model, but calculations need not treat it to solve chemical interactions of interest whenever the Temkin standard state is applied.

Model generated distributions of $\left(\mathrm{O}^{-}\right),\left(\mathrm{O}^{0}\right)$. $\left(\mathrm{O}^{2-}\right), n_{\mathrm{OH}}, n_{\mathrm{OH}^{-}}, n_{\mathrm{H}^{+}}$are plotted in fig. $7 \mathrm{a}, \mathrm{b}$ for the system $\mathrm{Na}_{5-4 x} \mathrm{Al}_{x} \mathrm{Si}_{3 x}(\mathrm{Al} / \mathrm{Si}=1 / 3)$ containing an arbitrary amount of water $(6 \mathrm{wt} \%$ in the whole compositional range) at $900^{\circ} \mathrm{C}$. We see that $\mathrm{H}^{+}$and $\mathrm{OH}^{-}$are always the predominant water derived species in melts, whereas $\mathrm{OH}$ are subordinated. In particular, abundances of $\mathrm{OH}^{-}$ anions and $\mathrm{H}^{+}$cations are inversely related, obtaining similar values at both low and high alumina contents. The abundance of $\mathrm{T}-\mathrm{OH}$ groups follows the same trend of $\mathrm{H}^{+}$cations, although much more smoothed. A slight increase in the concentration of free oxygen $\left(\mathrm{O}^{2-}\right)$ is computed for compositions with alumina content larger than that of albite $(X=1)$.

Finally, it is worth remarking that the appreciable occurrence of both eqs. (6.2) and (6.11) suggests a strong similarity with water behaviour in aqueous phase.

\section{Conclusions and perspectives}

The superiority of polymeric models in depicting silicte melts and slags reactivity with re- spect to other conceptual approaches is linked to the following facts:

i) It is well recognised that «regular mixture» models fail to reproduce the Gibbs free energy of mixing of silicate melts. Minima in the Gibbs free energy of mixing are badly allocated and badly conformed in the chemical space of interest. For heterogeneous equilibria (solid-liquid or liquid-gas in multicomponent systems) this problem is almost ineffective since internal consistency is achieved with extended databases encompassing model deviations through adjustable interaction parameters.

ii) The arbitrary deconvolution of chemically complex melts into fictive components is a path-dependent process eventually complicated by charge-balance considerations whenever amphotheric oxides are involved (this applies to iron and other transitional elements in slags and natural melts).

iii) Preliminary attempts to parameterise the bulk polymerisation proved satisfactory in deciphering the complex effect of the bulk LuxFlood acidity of the system on the oxidation state of iron in multicomponent melts and glasses (Ottonello et al., 2001). The Gibbs free energy of mixing of simple binaries $\mathrm{MO}-\mathrm{SiO}_{2}$ and of ternary systems $\left(\mathrm{CaO}-\mathrm{FeO}-\mathrm{SiO}_{2}\right)$ was successfully simulated (Ottonello, 2001).

iv) Polymeric models carry a minimal set of structural information which can be employed 
for the study of partitioning of elements, viscosity and - plausibly - other transport properties of silicate melts such as thermal and electrical conductivity.

The adopted polymeric parameterisation is based on three main previous observations:

1) The basicity of a complex aprotic medium such as a silicate melt or glass is conveniently represented by the «optical basicity», arising from the nephelauxetic effect induced on $p$-block metals by the ligand field (Duffy and Ingram, 1971, 1973, 1974a,b, 1976; Duffy and Grant, 1975).

2) Optical basicity is related to atomistic properties of the dissolved oxide components in the melts or glass, such as the Pauling and Sanderson electronegativities (Pauling, 1960; Sanderson, 1967) and the fractional ionic character of the bond (Pauling, 1960; Phillips, 1970).

3) Bulk optical basicity of molten silicates, or glasses can be split into two distinct contributions, the basicity of the dissolved basic oxides and the basicity of the polymeric units (or «structon matrix» in the sense of Fraser, 1975a,b, 1977). While the optical basicity effect induced by the dissolved oxides varies widely with the type of oxide component, the optical basicity effect ascribable to the structon matrix is virtually unaffected by composition, at parity of silica content in the system, and is dominant at high silica contents.

An exploratory application to the modelling of the oxidation state of iron shows that it is possible to extend the model of Ottonello et al. (2001) to hydrous aluminosilicate melts. This requires the introduction of volume terms for both ionic species and macroscopic components, together with equilibria relevant to water speciation. These preliminary results are quite satisfactory and promising, especially considering that the polymerisation constant employed represents the high- $T$ approximation (Ottonello and Moretti, 2004) and that I adopted experimental values for molar volumes, whereas more accurate partial molar volumes should be employed. In particular, data are well explained as long as both basic and acidic dissociations of water are considered.

A further slight amelioration to model precision may be introduced by accounting for a sub- sequent process of association to NBO's, that may be seen at first approximation as characteristic of strongly hydrogen-bonded T-OH groups. The fact that water also undergoes an acidic dissociation, originating free anions $\mathrm{OH}^{-}$, agrees with the recent findings of Xue and Kanzaki (2001, 2003), based on density functional theory, inferring the existence of $\mathrm{NaOH}$ groups in alkaline silicate glasses and confirms the prediction of Fraser (Fraser, 1975, 2003; and this issue).

It is worth stressing that the reliability of calibrated equilibrium constants involving ionic species of water and iron is subjected to i) the quality and $P-T-X$ extension of the reference database; and to ii) accurate estimates of reaction volumes of iron species and of reactions in which they are involved. Moreover, it must be clear that the present modelling does not have any straight implication about the geometry of coordination polyhedra in silicate melts, not required for the purposes of understanding polymerisation and the acid-base behaviour of investigated species. Therefore, ionic species depicted by the model are not necessarily related to structural units that can be identified by means of current spectroscopic tools.

In the light of these results, some future activity may be here planned, both experimental and theoretical. Some research lines may be proposed and followed contemporaneously to solve accurately, the mixing properties of silicate melts:

i) Experimental - in situ measurement of optical basicity (nephelaxeutic parameter) at $T$ and $P$.

ii) Experimental - XPS measurement of free oxygen $\left(\mathrm{O}^{2-}\right)$ in silicate melts coupled to the Toop-Samis modelling of silicate melts (see next point).

iii) Theoretical - application of the hybrid model of Ottonello (2001) to the conformation of liquidus in multicomponent systems, following the guidelines of the Flood and Grjotheim treatment for the calculation of chemical interactions coupled to strain energy modelling.

iv) Theoretical - by applying quantum-mechanical codes to simple binaries and ternaries; in order to better assess the nature of nephelauxetic effect in ligand field-related spectroscopic observations. 
The first task has the objective of improving the Toop-Samis model, by translating the $T$ dependence of nephelaxeutic parameters into polymerisation constants of the type of eq. (4.27). As required by the second task, this may also be done through XPS measurements of oxygen species, which coupled to predictions of the Fincham-Richardson approach allow a thorough assessment of polymerisation in melts (Park and Rhee, 2001). The third task has the objective of deciphering the contribution given by the dissociation of every component in chemical systems of increasing complexity. First we should reconstruct the binary $\mathrm{SiO}_{2}$ $\mathrm{Al}_{2} \mathrm{O}_{3}$ and then study ternary fields $\mathrm{MO}-\mathrm{Al}_{2} \mathrm{O}_{3}-$ $\mathrm{SiO}_{2}$. With the introduction of alumina it is important to investigate the effect of entropic effects, because of the similitude of acid-base properties with silica. Navrotsky (1994) pointed out that in this binary the $\mathrm{Al}^{3+}$ cation is forced to occupy the octahedral site. Entropic terms, arising from a «competitive» effect of $\mathrm{Al}_{2} \mathrm{O}_{3}$ and $\mathrm{SiO}_{2}$ upon the polymerisation are then expected to come out. Entropic terms should also be much more evident in the presence of alkalies in the system, mainly because of the charge compensation of the tetrahedral aluminum. The effects of non-random mixing of some network modifier oxides like $\mathrm{Na}_{2} \mathrm{O}$ and $\mathrm{K}_{2} \mathrm{O}$ must be carefully evaluated. Moreover, a systematic comparison, while creating the thermodynamic database, will allow us to further refine nephelauxetic parameters and their dependence upon intensive variables, especially in terms of temperature. Finally, we should also consider the mechanical strain energy contribution to the bulk free energy of mixing, since such a term explains the observed solvi experimentally determined in $\mathrm{SiO}_{2}$ rich ranges of binary systems. As shown by Ottonello and Moretti (2004) the plethora of thermodynamic data emerging from the metallurgical community is, to this purpose, of invaluable help. Some queries may be addressed to experimentalists, such as coupling optical basicity measurements with spectroscopic measurements on the Rydberg's and electron transfer emission lines of $3 \mathrm{~d}$ chromophores. This would allow us to assess better the differential nephelauxetic effects and the structural state of complexes.
The fourth research line is devoted to a better comprehension of model clusters and complexes which characterise the speciation state of silicate melts. A feasibility study for the adoption of parallel computing techniques has to be carried out. Semi-empirical methods, such as Huckel-MO, have to be ruled out as they need a large amount of experimental data, the consistency of which is often doubtful.

All the considerations here reported are preliminary to the set-up of an ambitious general thermochemical simulator able to depict the evolution of a complex (but essentially aprotic) system. Given such a general polymeric model, we can promote on its grounds thorough studies of water solubility (as well as any other volatile), through recalculation of equilibrium constants for both eqs. (6.2) and (6.11).

For our scientific community final applications will concern the study of the degassing of active volcanoes, the dynamics of magma flow and eruption, the interpretation of glass inclusion and plume composition analyses. Results will be also valuable for material scientists devoted to the physical chemistry of oxide systems.

\section{Acknowledgements}

I wish to thank Giulio Ottonello for his helpful comments to a preliminary version of this paper, and also for his continuous encouragement during recent years. The manuscript benefited of reviews by Don Fraser and Max Wilke. Mike Carroll is acknowledged for editorial handling. This work was carried out with the financial support of Regione Campania, L.R. 5/2002 grant for basic research.

\section{REFERENCES}

BAKER, L.L. and M.J. RUTHERFORD (1996): The effect of dissolved water on the oxidation of silicic melts, Geochim. Cosmochim. Acta, 60, 2179-2187.

Bockris, J.O’M. and G.W. Mellors (1956): Electric conductance in liquid lead silicates and borates, J. Phys. Chem., 60, 1321-1328.

Bockris J.O'M., J.A. KiTCHENER and A.E. DAVIES (1952a): Electric transport in liquid silicates, Trans. Faraday Soc., 48, 536-548. 
BOCKRIS, J.O'M., J.A. KITCHENER, S. IGNATOWIVZ and J.W. TOMLINSON (1952b): The electrical condctivity of silicate melts: systems containing $\mathrm{Ca}, \mathrm{Mn}, \mathrm{Al}$, Discuss. Faraday Soc., 4, 281-286.

Bockris, J.O'M., J.D. MACKENZIE and J.A. KitCHENER (1955): Viscous flow in $\mathrm{SiO}_{2}$ and binary liquid silicates, Trans. Faraday Soc., 51, 1734-1748.

Bottinga, Y., P. RicheT and D. Weill (1983): Calculation of the density and thermal expansion coefficient of silicate liquids, Bull. Mineral., 106, 129-138.

Bowen, N.L. (1928): The Evolution of Igneous Rocks (Princeton University Press).

Dingwell, D.B. and M. Brearley (1988): Melt densities in the $\mathrm{CaO}-\mathrm{FeO}-\mathrm{Fe}_{2} \mathrm{O}_{3}-\mathrm{SiO}_{2}$ system and the compositional dependence of the partial molar volume of ferric iron in silicate melts, Geoochim. Cosmochim. Acta, 52, 2815-2825.

Dingwell, D.B., M. Brearley and J.E. Jr. Dickinson (1988): Melt densities in the $\mathrm{Na}_{2} \mathrm{O}-\mathrm{FeO}-\mathrm{Fe}_{2} \mathrm{O}_{3}-\mathrm{SiO}_{2}$ system and the partial molar volume of tetrahedrally-coordinated ferric iron in silicate melts, Geochim. Cosmochim. Acta, 52, 2467-2475.

Douglas, R.W., P. NATH and A. Paul (1966): Authors' reply to the above comments, Phys. Chem. Glasses, 7, 213-215.

DufFy, J.A. (1992): A review of optical basicity and its applications to oxidic systems, Geochim. Cosmochim. Acta, 57, 3961-3970.

DufFy, J.A. (1996): Redox equilibria in glass, J. Non-Cryst. Solids, 196, 45-50.

DufFY, J.A. and R.J. GRANT (1975): Effect of temperature on optical basicity in the sodium oxide-boric oxide glass system, J. Phys. Chem., 79, 2780-2784.

DuFFY, J.A. and M.D. INGRAM (1971): Establishment of an optical scale for Lewis basicity in inorganic oxiacids, molten salts and glasses, J. Am. Ceram. Soc., 93, 64486454.

DuFFy, J.A. and M.D. IngRAM (1973): Nephelauxetic effect and Pauling electronegativity, J. Chem. Soc. Chem. Comm., 17, 635-636.

DuFFY, J.A. and M.D. INGRAM (1974a): Optical basicity-IV: Influence of electronegativity on the Lewis basicity and solvent properties of molten oxianion salts and glasses, J. Inorg. Nucl. Chem., 17, 1203-1206.

DuFFY, J.A. and M.D. IngRAM (1974b): Ultraviolet spectra of $\mathrm{Pb}^{2+}$ and $\mathrm{Bi}^{3+}$ in glasses, Phys. Chem. Glasses, 15 , 34-35.

DufFY, J.A. and M.D. IngRAM (1976): An interpretation of glass chemistry in terms of the optical basicity concept, J. Non-Cryst. Solids, 21, 373-410.

FINCHAM, C.J.B. and F.D. RiCHARDSON (1954): The behaviour of sulphur in silicate and aluminate melts, Proc. $R$. Soc. London, Ser. A, 223, 40-62.

Flood, H. and T. FöRlAND (1947): The acidic and basic properties of oxides. Acta Chem. Scand., 1, 952-1005.

Flood, H. and T. GRJOTHEIM (1952): Thermodynamic calculation of slag equilibria, J. Iron Steel Inst., 171, 64-80.

Flory, P.J. (1953): Principles of Polymer Chemistry (Cornell University Press, Ithaca-New York).

FRASER, D.G. (1975): Activities of trace elements in silicate melts. Geochim. Cosmochim. Acta, 39, 1525-1530.

FRASER, D.G. (1977): Thermodynamic properties of silicate melts, in Thermodynamics in Geology, edited by F.G.
Fraser (D. Reidel Pub. Co., Dortrecht-Holland).

FRASER, D.G. (2003): Acid-base properties, structons and the thermodynamic properties of silicate melts, Geochim. Cosmochim. Acta, 67 (suppl. to no. 18), abstr. 103.

FudALI, R.F. (1965): Oxygen fugacities of basaltic and andesitic magmas, Geochim. Cosmochim. Acta, 29, 10631075 .

Gaillard, F., B. Scaillet, M. Pichavant and J.-M. Bény (2001): The effect of water and $f \mathrm{O}_{2}$ on the ferric-ferrous ratio of silicic melts, Chem. Geol., 174, 255-273.

GASKELL, D.R. (1982): On the correlation between the distribution of phosphorous between slag metal and the theoretical optical basicity of the slag, Trans. Iron Steel Inst. Jpn., 22, 997-1000.

GASKELL, D.R. (2000): Early model of the thermodynamic behavior of slags and salts, in Proceedings of the Sixth International Conference on «Molten slags, fluxes and salts», Stockholm, Sweden - Helsinki, Finland, edited by S. SeEtharaman and Du Sichen, Paper 004.

GHIORSO, M.S. and R.O. SACK (1994): Chemical mass transfer in magmatic processes, IV. A revised internally consistent thermodynamic model for the interpolation and extrapolation of liquid-solid equilibria in magmatic systems at elevated temperatures and pressures, Contrib. Mineral. Petrol., 119, 197-212.

GHIORSO, M.S., I.S.E. CARMICHAEL, M.L. Rivers and R.O. SACK (1983): The Gibbs free energy of natural silicate liquids; an expanded regular solution approximation for the calculation of magmatic intensive variables, Contrib. Mineral. Petrol., 84, 107-145.

GoRDY, W. (1950): Interpretation of nuclear quadrupole couplings in molecules, J. Chem. Phys., 19, 792-793.

HERASYMENKo, P. (1938): Electrochemical theory of slagmetal equilibria, Part I. Reactions of manganese and silicon in acid open-heart furnace, Trans. Farad. Soc., 34, 1245-1254.

Hess, P.C. (1971): Polymer models of silicate melts, Geochim. Cosmochim. Acta, 35, 289-306.

HinZe, J.A., M.A. WhiteHEAD and H.H. JAFFE (1963): Electronegativity, II. Bond and orbital electronegativity, $J$. Inorg.Chem., 38, 983-984.

HolmQUIST, S. (1966): Ionic formulation of redox equilibria in glass melts, J. Am. Ceram. Soc., 49, 228-229.

JAMES, F. and M. Roos (1977): MINUIT: a System for Function Minimisation and Analysis of Parameter Errors and Correlations (CERN Computer Center Geneva, Switzerland)

JohnSTON, W.D. (1964): Oxidation-reduction equilibria in iron-containing glass, J. Am. Ceram. Soc., 47, 198-201.

JøRGENSEN, C.K. (1962): Absorption Spectra and Chemical Bonding in Complexes (Pergamon Press, Oxford).

JøRGENSEN, C.K. (1969): Oxidation Numbers and Oxidation States (Springer-Verlag, Berlin-Heidelberg-New York).

Kohn, S.C., R. DupreE and M.E. SMith (1989): A multinuclear magnetic resonance study of the structure of hydrous albite glasses, Geochim. Cosmochim. Acta, 53, 2925-2935.

Kowada, Y., H. Adachi, M. Tatsumisago and T. Minami (1995): Electronic states of transition metal ions in silicate glasses, J. Non-Cryst. Solids, 192, 316-320.

KRESS, V.C. and I.S.E. CARMICHAEL (1991): The compressibility of silicate liquids containing $\mathrm{Fe}_{2} \mathrm{O}_{3}$ and the effect of composition, temperature, oxygen fugacity and 
pressure on their redox states, Contrib. Mineral. Petrol., 108, 82-92.

LANGE, R.A. (1994): The effect of $\mathrm{H}_{2} \mathrm{O}, \mathrm{CO}_{2}$ and $\mathrm{F}$ on the density and viscosity of silicate melts, in Volatiles in Magmas, edited by M.R. CARROLL and J.R. HollowaY, Rev. Mineral., 30, 331-369.

LANGE, R.A. and I.S.E. CARMICHAEL (1989): Ferric-ferrous equilibria in $\mathrm{Na}_{2} \mathrm{O}-\mathrm{FeO}-\mathrm{Fe}_{2} \mathrm{O}_{3}-\mathrm{SiO}_{2}$ melts: effects of analytical techniques on derived partial molar volumes, Geochim. Cosmochim. Acta, 53, 2195-2204.

LiU, Y., H. NeKVASIL and H. LoNG (2002): Water dissolution in albite melts: constraints from $a b$ initio NMR calculations, Geochim. Cosmochim. Acta, 66, 4149-4163.

MAsson, C.R. (1965): An approach to the problem of ionic distribution in liquid silicates, Proc. R. Soc. London, A287, 201-221.

Masson, C.R., I.B. SMith and S.G. Whiteway (1970): Activities and ionic distributions in liquid silicates: application of polymer theory, Can. J. Chem., 48, 1456-1464.

Mo, X., I.S.E. Carmichael, M. Rivers and J. Stebbins (1982): The partial molar volume of $\mathrm{Fe}_{2} \mathrm{O}_{3}$ in multicomponent silicate liquids and the pressure dependence of oxygen fugacity in magmas, Min. Mag., 45, 237-245.

Moore, G., K. Righter and I.S.E. Carmichael (1995): The effect of dissolved water on the oxidation state of iron in natural silicate liquids, Contrib. Mineral. Petrol., 120, 170-179.

MoretTI, R. (2002): Volatile solubility in silicate melts with particular regard to sulphur species: theoretical aspects and application to etnean volcanics, Ph.D. Thesis (Università degli Studi di Pisa), (in English).

Moretti, R. and G. OtTonello (2003a): Polymerization and disproportionation of iron and sulfur in silicate melts: insights from an optical basicity-based approach, J. Non-Cryst. Solids, 323, 111-119.

Moretti, R. and G. Ottonello (2003b): A polymeric approach to the sulfide capacity of silicate slags and melts, Metall. Mat. Trans. B, 34B, 399-410.

Moretti, R., P. Papale and G. Ottonello (2003): A model for the saturation of C-H-O-S fluids in silicate melts, in Volcanic Degassing, edited by C. OPPENHEIMER, D.M. Pyle and J. Barclay, Geol. Soc. London Spec. Publ. 213, 81-101.

Mysen, B.O., I.S.E. Carmichael and D. Virgo (1985): A comparison of iron redox ratios in silicate glasses determined by wet-chemical and ${ }^{57} \mathrm{Fe}$ Mössbauer resonant absorption methods, Contrib. Mineral. Petrol., 90, 101-106.

Navrotsky, A. (1994): Physics and chemistry of Earth materials (Cambridge University Press, Cambridge, U.K.).

Otтonello, G. (1983): Trace elements as monitors of magmatic processes (1) limits imposed by Henry's Law problem and (2) compositional effect of silicate liquid, in The Significance of Trace Elements in Solving Petrogenetic Problems and Controversies, edited by $\mathrm{S}$. Augusthitis (Theophrastus Publications, Athens).

Ottonello, G. (1997): Principles of Geochemistry (Columbia University Press, New York-Chicester-West Sussex).

OtTONELlo, G. (2001): Thermodynamic constraints arising from the polymeric approach to silicate slags: the system $\mathrm{CaO}-\mathrm{FeO}-\mathrm{SiO}_{2}$ as an example, J. Non Cryst. Solids, 282, 72-85.

OtTonello, G. (2005): Chemical interactions and configu- rational disorder in silicate melts, Ann. Geophysics, 48 (4/5), 561-581 (this volume).

Ottonello, G. and R. Moretti (2004): Lux-Flood basiciy of binary silicate melts, J. Phys. Chem. Solids, 65, 1609-1614

Ottonello, G., R. Moretti, L. Marini and M. Vetuschi ZuCCOLINI (2001): On the oxidation state of iron in silicate melts and glasses: a thermochemical model, Chem. Geol., 174, 157-179.

PAPAlE, P. (1999): Modeling of the solubility of a two-component $\mathrm{H}_{2} \mathrm{O}+\mathrm{CO}_{2}$ fluid in silicate liquid, Am. Mineral., 84, 477-492.

PARK, J. and P.C. RHEE (2001): Ionic properties of oxygen in slags, J. Non-Cryst. Solids, 282, 7-14.

PAul, A. and R.W. Douglas (1965): Ferrous-ferric equilibrium in binary alkali silicate glasses, Phys. Chem. Glasses, 6, 207-211.

PAuling, L. (1932): Nature of the chemical bond, IV. The energy of single bonds and the relative electronegativity of atoms, J. Am. Chem. Soc., 54, 3570-3582.

PAuling, L. (1960): The Nature of the Chemical Bond (Cornell University Press, Ithaca-New York).

Pelton, A.D. (1998): Thermodynamic calculations of chemical solubilities of gases in oxide melts and glasses, Glastech. Ber. Glass Sci. Technol., 72 (7), 214-226.

Pelton, A.D. and M. Blander (1986): Thermodynamic analysis of ordered liquid solutions by a modified quasichemical approach-application to silicate slags, Metall. Trans. B, 17B, 805-815.

PhILLIPS, J.C. (1970): Ionicity of the chemical bond in crystals, Rev. Mod. Phys., 42 (3), 317.

REYES, R.A. and D.R. GASKELL (1983): The thermodynamic activity of $\mathrm{ZnO}$ in silicate melts, Metall. Trans. B, 14B, 725-731.

RYERSON, F.J. and P.C. HESS (1978): Implications of liquid distribution coefficients to mineral-liquid partitioning, Geochim. Cosmochim. Acta, 42, 921-932.

Ryerson, F.J. and P.C. HESS (1980): The role of $\mathrm{P}_{2} \mathrm{O}_{5}$ in silicate melts, Geochim. Cosmochim. Acta, 44, 611-624.

SANDERSON, R.T. (1967): Inorganic Chemistry (Reinhold Publ. Co., New York).

SCHENCK, H. (1945): Introduction to the Physical Chemistry of Steelmaking (BISRA, London, U.K.).

Schmidt, B.C., T. Riemer, S.C. Kohn, F. Holtz and R. DUPREE (2001): Structural implications of water dissolution in haplogranitic glasses from NMR spectroscopy: influence of total water content and mixed alkali effect, Geochim. Cosmochim. Acta, 65, 2949-2964.

SHANNON, R.D. (1976): Revised effective ionic radii and systematic studies of interatomic distances in halieds and chalcogenides, Acta Cryst., A32, 751-767.

ShibatA, K. (1967): The oxygen partial pressure of the magma from Mihara volcano, O-sima, Japan, Bull. Chem. Soc. Jpn., 40, 830-834.

SosinSKY, D.J. and I.D. SOMMERVILLE (1986): The composition and temperature dependence of the sulfide capacity of metallurgical slags, Metall. Trans. B, 17B, 331-337.

TEMkin, M. (1945): Mixtures of fused salts as ionic solutions, Acta Phys. Chim. URSS, 20, 411-420.

Toop, G.W. and C.S. SAMIS (1962a): Some new ionic concepts of silicate slags, Can. Met. Quart., 1, 129-152.

Toop, G.W. and C.S. SAMIS (1962b): Activities of ions in silicate melts, Trans. Met. Soc. AIME, 224, 878-887. 
VIRGO, D. and B.O. MYSEN (1985): The structural state of iron in oxidized versus reduced glasses at 1 atm: a ${ }^{57} \mathrm{Fe}$ Mössbauer study, Phys. Chem. Miner., 12, 65-76.

WAFFE, H.S. and D.F. WEILL (1975): Electrical conductivity of magmatic liquid effects of temperatures, oxygen fugacity and composition, Earth Planet. Sci. Lett., 28, 254-260.

WATsOn, E.B. (1976): Two-liquid partition coefficients: experimental data and geochemical implications, Contrib. Mineral. Petrol., 56, 119-134

WilKe, M., H. BEHRENS, D.M.J. BuRKHARD and S. RosSANO (2002): The oxidation state of iron in silicic melt at 500 Mpa water pressure, Chem. Geol., 189, 55-67.
Xue, X. and M. KANZAKI (2001): Ab initio calculation of the ${ }^{17} \mathrm{O}$ and ${ }^{1} \mathrm{H}$ NMR parameters for various $\mathrm{OH}$ groups: implications to the speciation and dynamics of dissolved water in silicate glasses, J. Phys. Chem. B, 105, 3422-3434.

Xue, X. and M. KanZaKi (2003): The dissolution mechanism of water in alkaline earth silicate and aluminosilicate melts: one view from ${ }^{1} \mathrm{H}$ MAS NMR, Geochim. Cosmochim. Acta, 67 (suppl. to no. 18), abstr. 543.

Young, R.W., J.A. Duffy, G.J. Hassall and Z. Xu (1992): Use of optical basicity concept for determining phosphorous and sulphur slag-metal partitions, Ironmaking Steelmaking, 19, 201-219. 